\title{
Cholinergic Neurotransmission in the Posterior Insular Cortex Is Altered in Preclinical Models of Neuropathic Pain: Key Role of Muscarinic M2 Receptors in Donepezil-Induced Antinociception
}

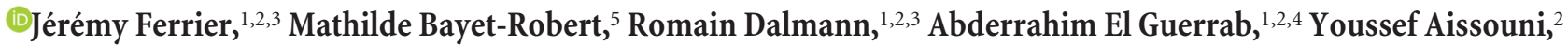 \\ Danielle Graveron-Demilly, ${ }^{6}$ Maryse Chalus, ${ }^{1,2,3}$ Jérémy Pinguet, ${ }^{3,7}$ Alain Eschalier, ${ }^{1,2,3,7}$ Damien Richard, ${ }^{3,7}$ \\ Laurence Daulhac, ${ }^{1,2,3}$ Fabien Marchand, ${ }^{1,2,3 *}$ and David Balayssac ${ }^{1,2,3,7 *}$ \\ ${ }^{1}$ Clermont Université, Université d'Auvergne, Pharmacologie Fondamentale et Clinique de la Douleur, F-63000 Clermont-Ferrand, France, ${ }^{2}$ Inserm, U1107 \\ NEURO-DOL, F-63001 Clermont-Ferrand, France, ${ }^{3}$ Institut Analgesia, F-63000 Clermont-Ferrand, France, ${ }^{4}$ Centre Jean Perrin, ERTICA EA4677 Université \\ d'Auvergne, F-63001, Clermont-Ferrand, France, ${ }^{5}$ Université Lyon, CNRS, ENS Lyon, UCB Lyon 1, Ctr RMN Très Hauts Champs, F-69100 Villeurbanne, \\ France, ${ }^{G}$ Université Lyon 1, Inserm U1044, CNRS UMR 5220, Laboratory CREATIS, F-69616 Villeurbanne, France, and ${ }^{7} \mathrm{CHU}$ Clermont-Ferrand, F-63000 \\ Clermont-Ferrand, France
}

Neuropathic pain is one of the most debilitating pain conditions, yet no therapeutic strategy has been really effective for its treatment. Hence, a better understanding of its pathophysiological mechanisms is necessary to identify new pharmacological targets. Here, we report important metabolic variations in brain areas involved in pain processing in a rat model of oxaliplatin-induced neuropathy using HRMAS ${ }^{1}$ H-NMR spectroscopy. An increased concentration of choline has been evidenced in the posterior insular cortex (pIC) of neuropathic animal, which was significantly correlated with animals' pain thresholds. The screening of 34 genes mRNA involved in the pIC cholinergic system showed an increased expression of the high-affinity choline transporter and especially the muscarinic M2 receptors, which was confirmed by Western blot analysis in oxaliplatin-treated rats and the spared nerve injury model (SNI). Furthermore, pharmacological activation of M2 receptors in the pIC using oxotremorine completely reversed oxaliplatin-induced mechanical allodynia. Consistently, systemic treatment with donepezil, a centrally active acetylcholinesterase inhibitor, prevented and reversed oxaliplatin-induced cold and mechanical allodynia as well as social interaction impairment. Intracerebral microdialysis revealed a lower level of acetylcholine in the pIC of oxaliplatin-treated rats, which was significantly increased by donepezil. Finally, the analgesic effect of donepezil was markedly reduced by a microinjection of the M2 antagonist, methoctramine, within the pIC, in both oxaliplatin-treated rats and spared nerve injury rats. These findings highlight the crucial role of cortical cholinergic neurotransmission as a critical mechanism of neuropathic pain, and suggest that targeting insular M2 receptors using central cholinomimetics could be used for neuropathic pain treatment.

Key words: acetylcholine; donepezil; insular cortex; metabolomics; neuropathy; oxaliplatin

\section{Significance Statement}

Our study describes a decrease in cholinergic neurotransmission in the posterior insular cortex in neuropathic pain condition and the involvement of M2 receptors. Targeting these cortical muscarinic M2 receptors using central cholinomimetics could be an effective therapy for neuropathic pain treatment.

\section{Introduction}

Neuropathic pain is one of the most debilitating conditions affecting millions of people worldwide. To date, no therapeutic strategies have been entirely satisfying, providing only partial neuropathic pain relief. A better knowledge of neuropathic pain mechanisms, especially at the supraspinal level, should help in finding new treatment opportunities.
Among neuropathic pain conditions, oxaliplatin, an anticancer drug widely used for the adjuvant treatment of advanced colorectal cancer (André et al., 2004), is responsible for incapacitating and dose-limiting neurotoxicity with two components: acute nerve hyperexcitability and chronic cumulative peripheral neuropathy. Oxaliplatin is responsible for acute sensory symptoms, including cold allodynia in $>90 \%$ of patients (Raymond et 
al., 1998a,b). These symptoms develop shortly after oxaliplatin infusion and are self-limiting, resolving in a few days but reoccurring following subsequent administrations (Reddy et al., 2015). With the repetition of chemotherapy cycles, some patients may develop chronic cumulative neuropathy (Tofthagen, 2010; Tofthagen et al., 2011) with symmetric, distal, primarily sensory polyneuropathy characterized by persistent paresthesia, distal numbness, and pain (Reddy et al., 2015). This neuropathic pain condition is very difficult to treat and often resistant to current analgesics drugs (Weickhardt et al., 2011; Hershman et al., 2014).

Over the past two decades, neuroimaging studies have evidenced that several brain structures, the so-called "pain matrix," could contribute to painful conditions and pain "chronicization." Although oxaliplatin-induced neuropathic pain results from peripheral nerve neurotoxicity, we suspect that brain centers may be involved in the development and/or the maintenance of chronic pain as for other neuropathic pain conditions. Indeed, many chronic painful states have been associated with activation/ deactivation and/or gray matter losses in various brain areas involved in pain processing, including the somatosensory cortices, insula, amygdala, cingulate gyrus, and thalamus (Apkarian et al., 2004; Kuchinad et al., 2007; DaSilva et al., 2008; Burgmer et al., 2009; Gustin et al., 2010). Therefore, changes in some of these brain areas might also participate in oxaliplatin-induced neuropathic pain.

Our aim was to investigate the metabolic changes in the brain pain matrix in a rat model of oxaliplatin-induced painful neuropathy (Ling et al., 2007), using the solid-state high resolution magic angle spinning proton nuclear magnetic resonance technique (HRMAS ${ }^{1} \mathrm{H}$-NMR). Several metabolic changes were observed, especially the choline concentration in the posterior insular cortex (pIC), which led us to investigate the pathophysiological role of pIC cholinergic neurotransmission and evaluate cholinergic agents as potential treatment for oxaliplatin-induced neuropathic pain symptoms. Our results demonstrated that the activation of the central cholinergic system within the pIC through the M2 muscarinic receptor was able to reduce neuropathic pain symptoms in the oxaliplatin pain model. Interestingly, the involvement of M2 receptors expressed in the pIC was also extended to another model of neuropathic pain induced by traumatic nerve injury (spared nerve injury). Together, these results provide new insights into the cortical regulation of neuropathic pain and open new perspectives of treatment.

\section{Materials and Methods \\ Animal models}

Experiments were conducted on 213 male Sprague Dawley rats (6 weeks old, weighing 150-175 g upon arrival, Charles River) according to the European Communities Council directive (86/609/EEC of 24 November 1986). Animals were housed 3 per cage, with water and food ad libitum, a 12:12 h light/dark cycle, and 50\% hygrometry. The procedures were

Received April 21, 2015; revised Nov. 2, 2015; accepted Nov. 7, 2015.

Author contributions: J.F., A.E., F.M., and D.B. designed research; J.F., M.B.-R., R.D., A.E.G., Y.A., D.G.-D., M.C., J.P., D.R., L.D., and D.B. performed research; J.F., Y.A., F.M., and D.B. analyzed data; J.F., A.E., F.M., and D.B. wrote the paper.

This work was supported by the Auvergne University, INSERM, and the local branch of the Ligue Contre le Cancer (French League Against Cancer). J.F. has received a PhD Grant from the regional council of Auvergne and the European Community. We thank the European jMRUI project (EC-HCM/ CHRX-CT94-0432, EC-TMR/ERBFMRXCT970160), FAST (FP6-MC-RTN-035801), and TRANSACT (FP7-PEOPLE-2012-ITN-316679).

The authors declare no competing financial interests.

*F.M. and D.B. contributed equally to this work.

Correspondence should be addressed to Dr. Fabien Marchand, INSERM U1107 NEURO-DOL, 28 place Henri Dunant, BP 38, 63000 Clermont-Ferrand Cedex 01, France. E-mail: fabien.marchand@udamail.fr.

DOI:10.1523/JNEUROSCI.1537-15.2015

Copyright $\odot 2015$ the authors $\quad 0270-6474 / 15 / 3516419-13 \$ 15.00 / 0$ approved by the local ethic committee CEMEA-Auvergne and received the following agreement numbers: CE27-10, CE16-11, and CE22-11. The experiments were performed according to the ARRIVE guidelines for animal research (Kilkenny et al., 2010).

Oxaliplatin was administered intravenously at $2 \mathrm{mg} / \mathrm{kg}$ twice a week for 4.5 weeks (on Mondays and Fridays, cumulative dose received: 18 $\mathrm{mg} / \mathrm{kg}$ ), as described by Ling et al. (2007). Animals of the control group received similar injections of oxaliplatin vehicle ( $5 \%$ glucose). Treatments (oxaliplatin or 5\% glucose) were randomized within each cage, and the experimenter was blinded to treatment administration.

The spared nerve injury (SNI) procedure was performed according to the method described previously by Decosterd and Woolf (2000). Briefly, rats were anesthetized with a mixture of ketamine $(75 \mathrm{mg} / \mathrm{kg})$ and xylazine $(10 \mathrm{mg} / \mathrm{kg})$. After skin and biceps femoris muscle incision, the right sciatic nerve was carefully exposed and the common peroneal and tibial nerves were tight ligated with 6.0 silk (Ethicon, Johnson and Johnson) and sectioned distal to the ligation with a micro-scissor, removing a maximum of $5 \mathrm{~mm}$ of the distal nerve stump. Great care was taken to avoid any contact with or stretching of the sural nerve branch. The muscle and skin were then sutured (Monocryl 5-0, Ethicon, Johnson and Johnson). Sham animals used for Western blot analysis underwent the same procedure as described above, but the right sciatic nerve was only exposed and left intact.

\section{Behavioral tests}

Assessment of mechanical allodynia. Mechanical pain thresholds were assessed using an electronic von Frey test (Bioseb). Rats were placed in plastic compartments on an elevated wire floor and left for habituation for $15 \mathrm{~min}$ before each experiment. The von Frey apparatus, consisting of a plastic tip fitted in a hand-held force transducer, was applied perpendicularly to the animal's hindpaw from below and the force applied was gradually increased until paw withdrawal. The maximum force applied (expressed in grams) to induce paw withdrawal was recorded automatically and used as a pain parameter.

Assessment of cold allodynia. Cold pain thresholds were assessed using the tail-immersion test (Ling et al., 2007). The lower two-thirds of the tail were dipped into a cold water bath maintained at $10 \pm 0.5^{\circ} \mathrm{C}$. Tail withdrawal latency (seconds) from cold water was used as a pain parameter, with a cutoff time set at $15 \mathrm{~s}$ to prevent any tissue injury. Each rat was initially habituated to handling by the experimenter to avoid any struggle or aversive reactions during the test.

Rotarod test. Motor coordination was assessed using the rotarod test (Bioseb). Before the test, rats were trained by placing them on the fixed rod for $5 \mathrm{~min}$ on 2 consecutive days and then on the rotating rod at a constant speed of $4 \mathrm{rpm}$ for $5 \mathrm{~min}$ for a further $2 \mathrm{~d}$. On the testing day, rats were placed on the rotating rod, and the acceleration speed was increased constantly from $4 \mathrm{rpm}$ to $40 \mathrm{rpm}$ over $5 \mathrm{~min}$. The endpoint was the latency to fall (seconds) from the rod for each animal.

Social interaction test. Pain assessment in rodents is often restricted to the measurement of stimulus-evoked reflexes that does not represent the entire complexity of the human pain experience (Cobos and PortilloSalido, 2013). Indeed, anxiety is a common feature of chronic pain patients. Thus, anxiety-like behaviors were assessed in rodents using the social interaction test performed in a $75 \times 75 \mathrm{~cm}$ squared arena in gray Plexiglas under dim light conditions (30 lux at the arena center) (Grégoire et al., 2014). Two rats, treated similarly and taken from two different cages, were placed at the center of the arena, and the time spent in social interaction (time spent sniffing, following, grooming, boxing and wrestling with each other) was counted for $10 \mathrm{~min}$. Between each assay, the arena was carefully cleaned with a wet tissue paper to distribute and minimize residual scents from previous rats.

\section{HRMAS ${ }^{1}$ H-NMR spectroscopy-based metabolomic analysis}

Sample preparation. Sixteen rats were used. Following longitudinal assessment of mechanical allodynia, rats were killed by decapitation at day 31 after the first oxaliplatin administration (i.e., $3 \mathrm{~d}$ after the last injection). Brains were then quickly dissected out, and coronal sections were obtained using a $1.0 \mathrm{~mm}$ rat brain slicer (Phymep). The following brain 
structures were removed from the left hemisphere on ice [coordinates of the coronal slices are indicated in buckets in $\mathrm{mm}$ relative to bregma (Paxinos and Watson, 1998)]: primary and secondary somatosensory cortices $(-2 ; 0)$, posterior insular cortex $(-2 ; 0)$, anterior cingulate cortex $(2 ; 0)$, prefrontal cortex $(5 ; 4)$, amygdala $(-2 ;-4)$, and periaqueductal gray matter $(-6 ;-8)$. The sampling process lasted $<5 \mathrm{~min}$, and samples were rapidly frozen in liquid nitrogen and stored at $-80^{\circ} \mathrm{C}$ to avoid biochemical degradation. Before metabolomic analysis, $\sim 20 \mathrm{mg}$ of frozen tissue was rapidly introduced in disposable Bruker $4 \mathrm{~mm}$ inserts (B4496) and filled with $\mathrm{D}_{2} \mathrm{O}$ (Eurisotop).

\section{HRMAS ${ }^{1} \mathrm{H}$-NMR spectroscopy}

NMR spectra were acquired on a Bruker Avance 700 spectrometer (proton frequency $700.09 \mathrm{MHz}$ ) equipped with a standard double resonance $\left({ }^{1} \mathrm{H}-{ }^{13} \mathrm{C}\right) 4 \mathrm{~mm}$ HRMAS probe head with $z$ gradient. Samples were spun at $3500 \mathrm{~Hz}$. A Bruker Cooling Unit was used to maintain the samples at $283 \mathrm{~K}$ throughout the process. One-dimension (1D) NMR spectra were acquired using a Carr-Purcell-Meiboom-Gill pulse sequence with presaturation of the water signal during the $2 \mathrm{~s}$ relaxation delay, a $1 \mathrm{~ms}$ echo time, and an acquisition time of $1.36 \mathrm{~s}$. A total of $32 \mathrm{~K}$ data points with 512 scans were acquired using a spectral width of $8403 \mathrm{~Hz}$, for a total acquisition time of $\sim 30 \mathrm{~min}$. All free induction decays were multiplied by an exponential function equivalent to a $0.3 \mathrm{~Hz}$ line-broadening factor before Fourier transformation.

\section{Metabolite quantification}

Quantification was performed with jMRUI version 5.0 software package (Stefan et al., 2009) (http://www.mrui.uab.es/mrui/) using the QUEST (Quantification based on Quantum ESTimation) quantitation algorithm (Ratiney et al., 2004, 2005; Graveron-Demilly, 2014). This procedure uses a metabolite database set simulated by quantum mechanics with NMR-SCOPE (NMR Spectra Calculation using OPErators) (GraveronDemilly et al., 1993) using spin parameters from Govindaraju et al. (2000). Seventeen metabolites were quantified: acetate (Ace), alanine (Ala), aspartate (Asp), creatine and phosphocreatine (Cr), choline (Cho), GABA, glutamate (Glu), glutamine (Gln), glutathione (GSH), glycerophosphocholine (GPC), glycine (Gly), lactate (Lac), myo-inositol (m-Ins), $N$-acetyl-aspartate (NAA), phosphocholine (PC), taurine (Tau), and scyllo-inositol (s-Ins). The amplitude of metabolite signals was normalized to the total signal amplitude, as described by Fauvelle et al. (2010). The reliability of quantification was indicated by the CramérRao lower bounds (CRBs) calculated by the jMRUI software, which correspond to the estimated SD of the fit of each metabolite amplitude. For most metabolites, we obtained CRB $\leq 10 \%$, except for Ace and s-Ins for which we obtained $\mathrm{CRB} \geq 30 \%$.

\section{Gene/protein expression}

$m R N A$ extraction and reverse transcription. Sixteen rats were used: 8 oxaliplatin-treated rats and 8 control rats ( $5 \%$ glucose). At day 31 after the first oxaliplatin or vehicle injection, rats were killed and the posterior insular cortices were dissected out from the left hemisphere and stored at $-80^{\circ} \mathrm{C}$ until analysis (as presented in the "Sample preparation"). Total RNA was extracted from pIC samples using RNeasy Mini-Kit (QIAGEN). RNA was then stored at $-80^{\circ} \mathrm{C}$ until cDNA synthesis and amplification reaction. RNA quality was checked by electrophoresis using a Bioanalyzer 2100 with RNA 6000 Nano LabChip and BioSizing A.02.11 software (Agilent Technologies). Forty nanograms of total RNA were reverse transcribed in a total volume of $20 \mu$ l using a High Capacity cDNA reverse transcription Kit (Applied Biosystems).

\section{TaqMan Low Density Array (TLDA)}

Quantitative RT-PCR analysis was performed with custom designed arrays in TLDA 384-well micro fluidic cards (Applied Biosystems). Each well contained specific, user-defined primers and 6-FAM labeled TaqMan MGB probes (6-carboxyfluorescein as FAM and dihydrocyclopyrroloindole tripeptide minor groove binder as MGB), capable of detecting a single gene. The card was configured into 4 identical 34 gene sets ( 8 samples per card in duplicate), including two housekeeping genes (rplp2 and 18S). Thirty-four genes coding for proteins involved in Ach neurotransmission/metabolism were selected based on the Kyoto Encyclopedia of Genes and Genomes metabolic pathways (http://www. genome.jp/kegg/) and literature review (Table 1). A total of $100 \mu \mathrm{l} \mathrm{reac}-$ tion mixtures with $50 \mu \mathrm{l} \mathrm{cDNA}$ templates (100 ng) and an equal volume of TaqMan universal master mix (Applied Biosystems) was added to each line of TLDA after gentle vortex mixing. The array was centrifuged twice at $331 \times g$ for $1 \mathrm{~min}$ to distribute the samples from the loading port into each well. The card was then sealed, and PCR amplification was performed using an Applied Biosystems Prism 7900HT sequence detection system (thermal cycler conditions: $2 \mathrm{~min}$ at $50^{\circ} \mathrm{C}, 10 \mathrm{~min}$ at $94.5^{\circ} \mathrm{C}$, and $30 \mathrm{~s}$ at $97^{\circ} \mathrm{C}$, and $1 \mathrm{~min}$ at $59.7^{\circ} \mathrm{C}$ for 40 cycles). The threshold cycle $\left(C_{t}\right)$ was given automatically by the SDS version 2.2 software package. Relative quantities (RQs) were determined using the equation: $R Q=2^{-\Delta \Delta C t}$ (Livak and Schmittgen, 2001). All data are presented as log base $2(\log 2)$ of normalized fold change (FC) relative to samples from the vehicle injected rats. We used the $\log 2$ to allow visualization of the fold change in the positive (upregulated) and negative (downregulated) directions where 0 equals no change in gene expression, 1 and -1 equal twofold upregulation and downregulation, respectively.

\section{Expression of M2 receptor protein in the pIC}

Twenty rats were used in total: 5 oxaliplatin-treated rats and 5 control rats (5\% glucose) as well as $5 \mathrm{SNI}$ and 5 sham. At day 31 after the first oxaliplatin or vehicle injection, rats were killed and the posterior insular cortices were dissected out from the left hemisphere and stored at $-80^{\circ} \mathrm{C}$ until analysis. One month after nerve injury or sham surgery, rats were also killed by decapitation and the left posterior insular cortices (i.e., contralateral to the nerve injury) were dissected out, snap frozen in liquid nitrogen, and stored at $-80^{\circ} \mathrm{C}$ until analysis. Tissue samples were subsequently homogenized in RIPA (radioimmunoprecipitation assay) buffer (50 mm Tris HCl, pH 7.5, $150 \mathrm{~mm} \mathrm{NaCl}, 1$ mм EDTA, 1\% NP-40, 0.1\% SDS $+0.5 \%$ deoxycholic acid containing complete protease inhibitor mixture) using a glass homogenizer. Homogenates were then centrifuged at $14,000 \mathrm{rpm}$ for $10 \mathrm{~min}$ at $4^{\circ} \mathrm{C}$ and supernatants were collected. Wholecell lysates were titrated to determine total protein concentrations using a BCA Protein Assay kit (Pierce).

For Western immunoblotting, lamaelli loading buffer was added to the samples containing equal weight of total proteins $(30 \mu \mathrm{g})$ and heated at $95^{\circ} \mathrm{C}$ for $5 \mathrm{~min}$. Samples were then separated by SDS-PAGE using $10 \%$ acrylamide gels and transferred to nitrocellulose membranes using BioRad wet blotting system.

All membrane incubations were performed on a rotating plate. Washes were done in TBS-T $(50 \mathrm{~mm}$ Tris- $\mathrm{HCl}$ and $6 \mathrm{~mm} \mathrm{NaCl}$ containing $0.1 \%$ Tween 20 ). Blocking of unspecific binding sites was achieved by incubating membranes in 5\% nonfat dry milk in TBS-T for $1 \mathrm{~h}$ at room temperature. Membranes were then incubated with the primary antibodies directed against the muscarinic M2 receptors (1:1500, ab109226, Abcam) and $\beta$-actin (1:5000, Sigma-Aldrich) diluted in 5\% nonfat milk in TBS-T overnight at $4^{\circ} \mathrm{C}$. After washing, the membranes were probed with appropriate HRP-conjugated secondary antibodies diluted at 1:10,000 in 5\% nonfat dry milk in TBS-T for $1 \mathrm{~h}$ at room temperature. The immunoreactive bands were quantified by densitometric analysis using Bio-Rad imaging software (Chemidoc). The M2 band (i.e., $52 \mathrm{kDa}$ ) of each sample was normalized relative to the corresponding $\beta$-actin band.

\section{Pharmacological studies: assessment of the analgesic effect of a muscarinic agonist injected into the pIC}

Surgery. Fifty-one rats were used for this experiment. Surgery was performed between days 21 and 23 after the first oxaliplatin or $5 \%$ glucose injection. Rats were deeply anesthetized with a mixture of ketamine (75 $\mathrm{mg} / \mathrm{kg})$ and xylazine $(10 \mathrm{mg} / \mathrm{kg})$ and placed in a small animal stereotaxic frame (model 940, David Kopf instruments); $11 \mathrm{~mm}$ guide cannulas were then bilaterally implanted into the pIC using coordinates from Paxinos and Watson (1998): $-2.30 \mathrm{~mm}$ posterior and $6 \mathrm{~mm}$ lateral to bregma, and $5.5 \mathrm{~mm}$ ventral to the surface of the brain. The guides were fixed on the skull using dental cement (Henry Schein) and 3 anchoring surgical 
Table 1. Metabolite composition of various brain areas in oxaliplatin-treated animals and controls (in normalized arbitrary units) ${ }^{a}$

\begin{tabular}{|c|c|c|c|c|c|c|c|c|c|c|c|c|}
\hline \multirow[b]{2}{*}{ Metabolites } & \multicolumn{3}{|l|}{ Amygdala } & \multicolumn{3}{|c|}{ Anterior cingulate cortex } & \multicolumn{3}{|c|}{ Periaqueductal gray } & \multicolumn{3}{|c|}{ Posterior insular cortex } \\
\hline & S Control & liplatin & $p$ & Control & xaliplatin & $p$ & Control & Oxaliplatin & $p$ & ntrol & Oxaliplatin & $p$ \\
\hline e & $014 \pm 0.001$ & $017 \pm 0.001$ & 0.248 & $02 \pm 0.001$ & $0.0018 \pm 0.001$ & 0.5286 & $0.0021 \pm 0.001$ & $0.0026 \pm 0.001$ & 0.203 & $0.0014 \pm 0.001$ & $0.0013 \pm 0.001$ & 0.9164 \\
\hline & 001 & $0040 \pm 0.001$ & 0.674 & $0.0037 \pm 0.001$ & $0.004 \pm 0.0005$ & & $0.0033 \pm 0.001$ & $0.0032 \pm 0.001$ & & $0.0041 \pm 0.001$ & $0.0041 \pm 0.001$ & 0.8336 \\
\hline$n$ & $0.0054 \pm 0.003$ & 0.002 & 0.46 & 0.0052 & $0.0048 \pm 0.001$ & & 2 & $0.0070 \pm 0$ & & .001 & 0.0034 & 0.0063 \\
\hline 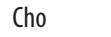 & $0.0022 \pm 0.001$ & .001 & 0 & $0.0042 \pm 0.001$ & $0.0046 \pm 0.001$ & & $0.0047 \pm 0.001$ & $0.0047=$ & 0.817 & $0.0027 \pm 0.0003$ & $0.0033 \pm 0.0004$ & 40.0046 \\
\hline & $0.0299 \pm 0.006$ & .004 & 1 & $0.0297 \pm 0.008$ & $0.0301 \pm$ & 1 & $0.0292 \pm 0.003$ & $0.0320 \pm 0.005$ & & $0.0312 \pm 0.003$ & $0.0276 \pm 0.004$ & 0.046 \\
\hline$n$ & $144 \pm$ & 004 & 0.4 & $0.0141 \pm 0.002$ & $0.0159=$ & & $0.0254 \pm 0.002$ & $0.0246 \pm 0.001$ & & & $0.0151 \pm 0.002$ & 0.7527 \\
\hline u & $887 \pm$ & 005 & & & 0.0392 & & & & & & & 0.3446 \\
\hline$n$ & 002 & 02 & & & 002 & & & & & & & 0.0209 \\
\hline H & $0.0064 \pm$ & 002 & & & 0.005 & & & & & & & 0.5286 \\
\hline C & 000 & 01 & 0.248 & & & & & & & & & 0.1722 \\
\hline Gly & 001 & 02 & 0.6744 & & & & & & & & & 0.3446 \\
\hline Lac & & & & & & & & & & & & 0.248 \\
\hline -Ins & & & & & & 1 & & & & & & 0.5286 \\
\hline NAA & & & & & & & & & & & & 4622 \\
\hline 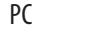 & & & & & & & & & & & & 0.4008 \\
\hline$s-\ln s$ & & & & & & & & & & & & 0.8336 \\
\hline \multirow[t]{2}{*}{ Tau } & & & & & $0.0251 \pm 0$ & 1 & $0.0059 \pm 0.002$ & $0.0067 \pm 0.00$ & & $0.0267 \pm$ & & 0.5995 \\
\hline & \multicolumn{3}{|l|}{ Prefrontal cortex } & \multicolumn{3}{|c|}{ Primary somatosensory cortex } & \multicolumn{3}{|c|}{ Secondary somatosensory cortex } & \multicolumn{3}{|l|}{ Thalamus } \\
\hline Metabolit & & 0xalip & $p$ & 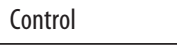 & & $p$ & & & $P$ & & & \\
\hline & & & & & & & & & & & & 50 \\
\hline & & & & & & & & & & & & 0.4622 \\
\hline 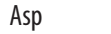 & 002 & & & & & & & & & & & \\
\hline & .001 & & & & .002 & & & & & & 02 & 0.1722 \\
\hline (I) & .004 & & & & 006 & & & & & & 06 & 0.9164 \\
\hline GABA & 002 & & & & 001 & & & & & & & 0.0357 \\
\hline Glu & 0.005 & 003 & 0 & 08 & .005 & & & & & & 05 & 0.4622 \\
\hline Gln & $32 \pm 0.002$ & 003 & 0 & 03 & 0.001 & & & & & & 01 & 0.5286 \\
\hline GSH & $0.0060 \pm 0.002$ & 0.0058 & 0.8973 & $0.0054 \pm 0.002$ & 0.0061 & & & 0.00 & & 0.0 & 001 & 0.4008 \\
\hline GPC & $0.0012 \pm 0.0003$ & 0.0015 & 0.1967 & $0.0010 \pm 0.0004$ & 0.0013 & 0.2 & 0.00 & 0.00 & 0. & 0.00 & 0.001 & 0.0357 \\
\hline Gly & $061 \pm 0.001$ & .001 & 0.51 & $0.0081 \pm 0.006$ & $0.0067 \pm 0.003$ & 0. & 0.00 & $0.0072=$ & 0.3 & $0.0081=$ & $=0.003$ & 0.248 \\
\hline Lac & $0.0460 \pm 0.008$ & $0.0446=$ & 0.89 & $0.0429 \pm 0.005$ & $0.0447 \pm 0.009$ & 0.6 & $0.0432 \pm$ & 0.0444 & & $0.0429=$ & \pm 0.009 & 0.6744 \\
\hline m-Ins & $0.0284 \pm 0.004$ & 003 & 0.89 & $0.0322 \pm 0.007$ & $0.0287 \pm 0.006$ & 0.4 & 0.0301 & 0.031 & & $0.0322 \pm 0.007$ & $0.0287 \pm 0.006$ & 0.7527 \\
\hline NAA & $0.0403 \pm 0.005$ & 0.0367 & 0.09 & $0.0417 \pm 0.008$ & 0.0457 & 0.2 & 0.0471 & 0.047 & & $0.0417=$ & \pm 0.003 & 0.0587 \\
\hline PC & $0.0045 \pm 0.001$ & 0.0044 & 0.79 & $0.0042 \pm 0.001$ & 0.0035 & & & 0.00 & & 0.0042 & .001 & 0.4622 \\
\hline$s-\ln$ & 0. & 0.0016 & 0.69 & $0.0018 \pm 0.001$ & 0.0013 & & & 0.00 & & 0.0018 & $0.0013=$ & 0.0929 \\
\hline Tau & $0.0266 \pm 0.001$ & $0.0254 \pm 0.003$ & 0.5186 & $0.0193 \pm 0.006$ & $0.0196 \pm 0.003$ & 0.4622 & $0.0197 \pm 0.003$ & $0.0194 \pm 0.002$ & 0.67 & $0.0193 \pm 0.006$ & $0.0196 \pm 0.003$ & 0.9164 \\
\hline
\end{tabular}

${ }^{a}$ Data are mean \pm SD. Statistical differences between groups were assessed using the nonparametric Mann-Whitney Wilcoxon test; $n=8 /$ group.

screws. After the surgery, $11 \mathrm{~mm}$ cap mandrels were inserted into the cannulas to avoid obstruction. Animals were then monitored until recovery from anesthesia and daily after surgery. Local antibiotic treatment (thiamphenicol) was administered to prevent postoperative infection. Drug infusion. Rats were anesthetized with $4 \%$ isoflurane and then maintained at $2 \%$ and drug solutions $(0.2 \mu \mathrm{l} /$ side $)$ were infused into the $\mathrm{pIC}$ at a constant rate over $90 \mathrm{~s}$ using $1 \mu \mathrm{l}$ Hamilton syringes, just after the measurement of baseline mechanical thresholds. The injection cannulas were left in place for an additional $30 \mathrm{~s}$ to allow diffusion of the drug solution. The following compounds were injected: the nonselective muscarinic agonist oxotremorine (sesquifumarate salt, $0.1 \mathrm{nmol}$, SigmaAldrich), the selective $\mathrm{M} 2$ receptor antagonist methoctramine $(30 \mathrm{nmol}$, Sigma-Aldrich), or both oxotremorine $(0.1 \mathrm{nmol})$ and methoctramine $(30 \mathrm{nmol})$. The doses of oxotremorine and methoctramine used were chosen from Power et al. (2003). Control animals received infusion of the vehicle solution $(0.9 \% \mathrm{NaCl})$. Treatments were randomized within each cage. Pharmacological evaluation was performed on day 31 after the first oxaliplatin injection, namely, 1 week after surgery. A behavioral test using the electronic von Frey was performed before drug administration (baseline values) and $15 \mathrm{~min}$ after.

At the end of the experiment, rats were killed with an overdose of pentobarbital $(100 \mathrm{mg} / \mathrm{kg})$. Brains were collected fresh in Prussian blue solution (potassium ferrocyanide) to stain the needle track and to confirm the infusion site. After histological examination, 7 rats were found to have at least one infusion needle terminating outside the pIC and were therefore excluded from analysis.

\section{Assessment of the analgesic effect of oral donepezil}

Donepezil (Aricept $10 \mathrm{mg}$, Pfizer,) pills, a reversible acetylcholinesterase inhibitor, were crushed to powder with a mortar and pestle, and then dissolved in $0.5 \%$ carboxymethylcellulose (Sigma-Aldrich) in water at a concentration of $5 \mathrm{mg} / \mathrm{ml}$. To determine the effect of donepezil on motor coordination using the rotarod test, rats received donepezil $10 \mathrm{mg} / \mathrm{kg}, 5$ $\mathrm{mg} / \mathrm{kg}$ or vehicle ( $n=8$ /group) by oral gavage (p.o.). Rotarod performances were assessed $1 \mathrm{~h}$ after administration.

Thirty two rats were used to test the curative effect of acute administration of donepezil on oxaliplatin-induced cold and mechanical allodynia. The animals were randomly assigned to receive either oxaliplatin or its vehicle. Mechanical and cold pain thresholds were assessed using the electronic von Frey test and the tail-immersion test, respectively. At the end of oxaliplatin administration (i.e., day 31$)$, half the rats $(8$ oxaliplatin-treated rats and 8 matched controls) received donepezil (5 $\mathrm{mg} / \mathrm{kg}$, p.o.) and the other half received the vehicle (p.o.), just after the baseline threshold measurement. Nociceptive thresholds were then assessed 30, 60, and $120 \mathrm{~min}$ after drug administration. To reduce the number of animals used for this study, mechanical and cold hypersensitivities were assessed on the same batch of rats.

As neuropathy is a predictable adverse effect of oxaliplatin, the preventive effect of repeatedly administered donepezil $(5 \mathrm{mg} / \mathrm{kg}$, p.o., twice a day) was explored starting just before the onset of symptoms, namely, before the fifth oxaliplatin injection (i.e., day 15). Thirty-two rats were randomly assigned to receive either oxaliplatin or its vehicle. Half the rats 
were treated with donepezil ( $5 \mathrm{mg} / \mathrm{kg}$, p.o., twice a day) for $14 \mathrm{~d}$. The other half received the same oral administrations of donepezil vehicle.

Because of the impact of neuropathic pain experience on social interaction (Grégoire et al., 2014), we assessed the effect of donepezil (5 mg/ $\mathrm{kg}$, p.o.) or its vehicle on the social interaction test in oxaliplatin-treated rats and matched controls $1 \mathrm{~h}$ after administration.

Finally, to determine the involvement of pIC M2 receptors in the analgesic effect of donepezil, the effect of methoctramine injected bilaterally into the pIC was tested in oxaliplatin-treated rats and SNI animals. Thirty-two rats, previously treated with oxaliplatin and subjected to the von Frey test, were divided into four groups: vehicle + saline; vehicle + methoctramine $(30 \mathrm{nmol})$; donepezil $(5 \mathrm{mg} / \mathrm{kg}$, p.o. $)+$ saline; donepezil $(5 \mathrm{mg} / \mathrm{kg}$, p.o. $)+$ methoctramine $(30 \mathrm{nmol})$. To extend these results to another model of neuropathic pain arising from traumatic nerve injury, this experiment was repeated on thirty two SNI rats. SNI rats, previously implanted with bilateral cannulas within the pIC, according to the method described, were injected using the same method as described above for the model of oxaliplatin-induced peripheral neuropathy, one month after nerve injury.

All pharmacological experiments were performed in a randomized block design to control variability and avoid any unspecific effects across the experiment. The experimenter was blind regarding the treatment administered.

\section{Effect of donepezil on acetylcholine levels in the pIC}

Surgery for microdialysis. Thirteen rats were used in this experiment. Following anesthesia using a mixture of ketamine $(75 \mathrm{mg} / \mathrm{kg}$, i.p. $)$ and xylazine $(10 \mathrm{mg} / \mathrm{kg}$, i.p.), rats were secured in a stereotaxic frame with ear and incisor bars. Microdialysis guide cannula (CMA 11; CMA/Microdialysis) were implanted and secured into the left caudal agranular insular cortex using dental cement and three anchoring screws (anterior-posterior: $-2.3 \mathrm{~mm}$; medial-lateral: $6.0 \mathrm{~mm}$; dorsal-ventral: $-4.5 \mathrm{~mm}$ ). Following surgery, animals were individually housed in cages with food and water ad libitum. Local antibiotic treatment (thiamphenicol) was administered to prevent postoperative infection. Daily observation and care were provided to animals.

\section{Microdialysis}

Microdialysis was performed 1 week after surgery, between day 29 and day 31 after the first injection of oxaliplatin or 5\% glucose in a randomized controlled manner. Microdialysis probes (CMA 11, membrane length $2 \mathrm{~mm}, 6000 \mathrm{Da}$ cutoff, CMA/Microdialysis) were perfused with $\operatorname{aCSF}(\mathrm{Na}=147 \mathrm{~mm}, \mathrm{~K}=4 \mathrm{~mm}, \mathrm{Ca}=2.25 \mathrm{~mm}, \mathrm{Cl}=155.5 \mathrm{~mm}$; Macopharma) containing $0.25 \mathrm{~mm}$ ascorbic acid to prevent Ach degradation. The probe was implanted into the pIC via the guide cannula under light anesthesia ( $0.5 \%$ isoflurane). A $2.5 \mathrm{~h}$ equilibration period was provided before dialysate collection to allow the tissue to recover from the physical damage caused by probe implantation (Zapata et al., 2009). The probes were perfused with aCSF at a flow rate of $2 \mu \mathrm{l} / \mathrm{min}$ and samples $(30 \mu \mathrm{l})$ were collected every $15 \mathrm{~min}$. After $2.5 \mathrm{~h}$ of baseline collection (10 samples), rats were treated with donepezil ( $5 \mathrm{mg} / \mathrm{kg}$, p.o.) or its vehicle and microdialysis samples were collected for a further $2.5 \mathrm{~h}$. At the end of the experiment, rats were killed by pentobarbital overdose $(100 \mathrm{mg} / \mathrm{kg}$, i.p.) and probe placement was verified histologically.

\section{Sample preparation for acetylcholine assay}

Stock solutions of Ach and $\beta$-methyl-Ach (acetylcholine chloride, acetyl$\beta$-methylcholine chloride; Sigma-Aldrich) were prepared at $1 \mathrm{mg} / \mathrm{ml}$ in $0.1 \%(\mathrm{v} / \mathrm{v})$ formic acid in water and stored at $4^{\circ} \mathrm{C}$. The analysis samples were prepared by spiking $10 \mu \mathrm{l}$ of internal standard $\beta$-methyl-ACh (10 $\mathrm{ng} / \mathrm{ml}$ in $0.1 \%$ formic acid) into $10 \mu \mathrm{l}$ of dialysate followed by vortexing. Standards and quality control samples were prepared by spiking $10 \mu \mathrm{l}$ of internal standard into $10 \mu \mathrm{l}$ of ACh stock solution diluted in aCSF. Eleven point calibration curves were constructed in the concentration ranges of $0.05-100 \mathrm{ng} / \mathrm{ml}$ and 3 quality controls (lower, medium, and upper level quantification) were performed in duplicate.

\section{Liquid chromatography and mass spectrometry}

Ten microliters of standard and sample preparations were injected into a liquid chromatography system (LC-20ADxr, Shimadzu). Chromatographic separation was performed using reverse-phase liquid chromatography at $30^{\circ} \mathrm{C}$ using a Hypersil pentafluorophenyl column $(150 \times 2.1$ $\mathrm{mm}, 5 \mu \mathrm{m}$; Thermo Fisher Scientific), and a gradient system with the mobile phase consisting of solvent A $(0.1 \%(\mathrm{v} / \mathrm{v})$ formic acid in water) and solvent $\mathrm{B}(0.1 \%(\mathrm{v} / \mathrm{v})$ formic acid in acetonitrile) at a flow rate of 200 $\mu \mathrm{l} / \mathrm{min}$. Run time was set to $11 \mathrm{~min}$. During the first $2.3 \mathrm{~min}$, the sample was directed to the waste through the divert valve. The autosampler was kept at $4^{\circ} \mathrm{C}$. On-line LC-MS/MS analyses were performed in a system consisting of a 5500 QTrap triple quadrupole linear ion trap mass spectrometer equipped with a Turbo IonSpray source operated in electrospray mode (AB Sciex). MS experiments were performed with a multiple reaction monitoring condition in positive mode, and settings were optimized to reach the highest signal intensity. The multiple reaction monitoring transitions of $\mathrm{m} / z 146.1 \rightarrow 87.0$ for ACh and $160.1 \rightarrow 100.9$ for $\beta$-methyl-ACh were monitored simultaneously. The concentrations of Ach in microdialysates were determined by their area ratios to that of the internal standard using a weighting quadratic fit. The quantification limit for Ach was $50 \mathrm{pg} / \mathrm{ml}$. Analyst version 1.5.2 and Multiquant 2.1 were used for data acquisition and analysis, respectively.

\section{Statistical analysis}

For the metabolomic analysis and TLDA experiment, statistical comparisons between control and treated groups were performed using the nonparametric Mann-Whitney Wilcoxon test. For the behavioral tests, mean \pm SD values were calculated for each group of treatment. The normality of the distribution was assessed using the Shapiro-Wilk test. To compare the time course evolution of different parameters, a repeated-measures ANOVA using mixed models was used to determine the effect of time and treatment. If a significant interaction between time and group was observed, a one-way ANOVA was performed for all time points using an appropriate post hoc test (see figure legends). Results, expressed as the mean $\pm \mathrm{SD}$, from the M2 Western blot analysis, were analyzed using the nonparametric Mann-Whitney Wilcoxon test. A $p$ value $<0.05$ was considered significant in all cases. Statistical analysis was performed using XLSTAT software version 2013.3.03 (Addinsoft).

\section{Results}

\section{Metabolite variations in the pain matrix}

Animals treated with oxaliplatin exhibited mechanical allodynia from day 14 ( $p=0.022$ ) up to the end of the experiment (i.e., day $31, p<0.001$ ) compared with the vehicle-treated group (Fig. 1A). Brain metabolite changes were assessed in the same animal groups (an example of spectra is shown in Fig. $1 B$ ). Of the 7 brain areas analyzed, significant metabolic changes between oxaliplatin-treated and control rats were only observed in the pIC and the thalamus (Table 1). In the pIC, a significant decrease in Asp $(-41 \%, p=0.0063)$, tCr $(-11 \%, p=0.046)$, and Gln $(-18 \%, p=0.0209)$ concentrations and an increase in Cho $(22 \%, p=0.0046)$ concentration were observed in oxaliplatintreated rats compared with control group (Fig. $1 C$ ). In the thalamus, a significant increase in GPC level $(31 \%, p=0.0357)$ was observed in oxaliplatin-treated animals as well as a decrease in GABA level $(-14 \%, p=0.0357)$ compared with control group (Table 1). Linear regressions were performed for all significant metabolic variations and mechanical withdrawal thresholds at day 31. Only the concentrations of Cho in the pIC were significantly and negatively correlated with mechanical paw withdrawal thresholds $(r=-0.6931, p=0.0029$; Fig. $1 D)$.

\section{Expression of genes involved in cholinergic neurotransmission/metabolism in the pIC}

The expression of 34 different genes involved in cholinergic neurotransmission/metabolism within the $\mathrm{pIC}$ was then explored using 

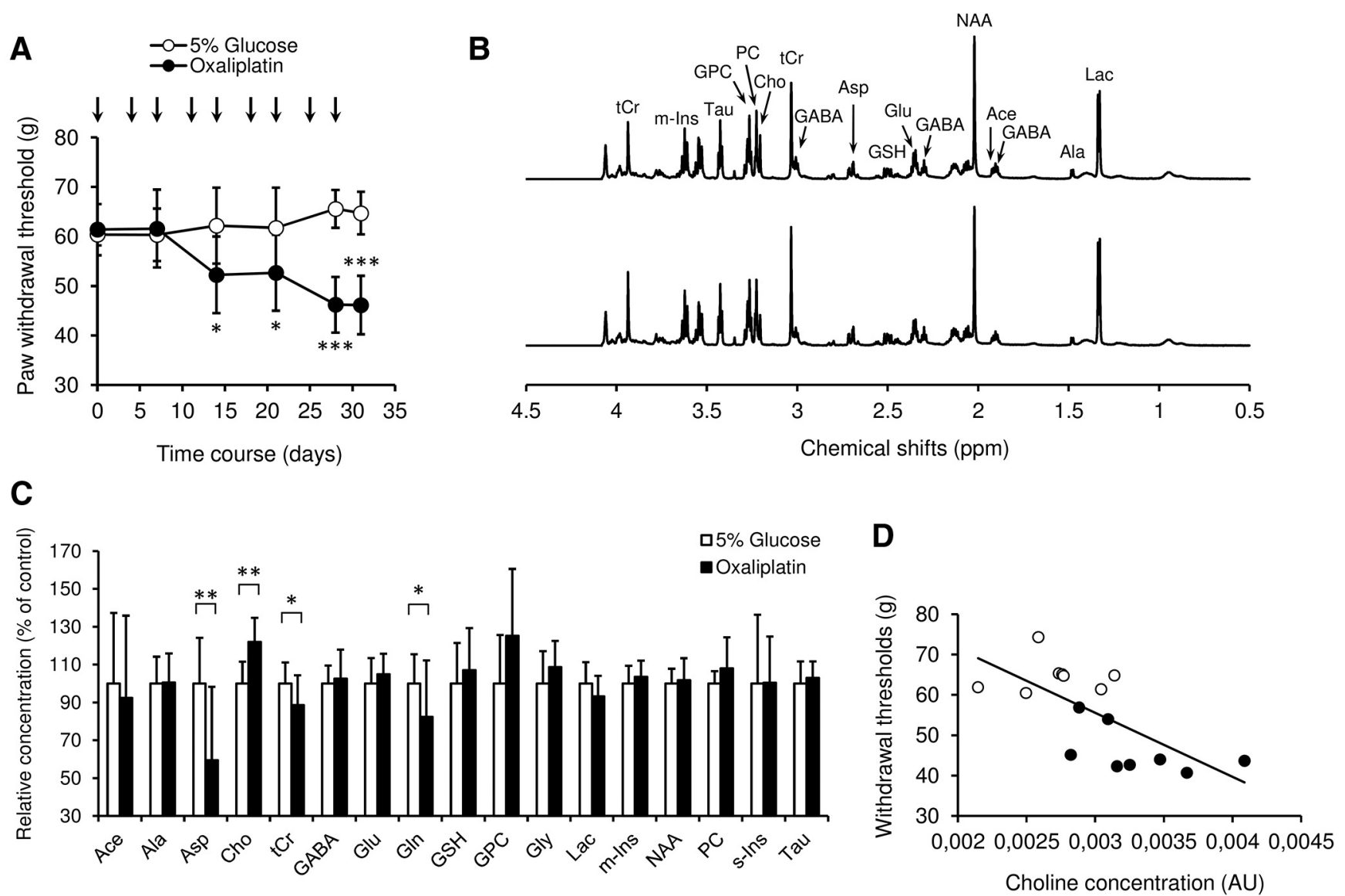

Figure 1. A, Time course of static mechanical allodynia in the electronic von Frey test. Data are mean $\pm S D .{ }^{*} p<0.05$ (two-way repeated-measures ANOVA followed by a Dunnett post hoc test). ${ }^{* * *} p<0.001$ (two-way repeated-measures ANOVA followed by a Dunnett post hoc test). $n=8 /$ group. $\boldsymbol{B}$, Representative HRMAS ${ }^{1} \mathrm{H}$-NMR spectra obtained at $700 \mathrm{MHz}$ from a posterior insular cortex sample of an oxaliplatin-treated rat (top) and a control (bottom). C, Relative concentrations of 17 metabolites in the posterior insular cortex of oxaliplatin-treated rats (black bars) and controls (white bars). Data are percentage of controls (mean \pm SD). ${ }^{*} p<0.05$ (nonparametric Mann-Whitney Wilcoxon test), ${ }^{* *} p<0.01 . n=8 /$ group. $D$, Pearson linear regression showing significant correlation between mechanical withdrawal thresholds $(\mathrm{g})$ and choline concentration in the posterior insular cortex in arbitrary units (AU). $r=-0.6931, p<0.01$.

TLDA (Table 2). In oxaliplatin-treated rats compared with controls, increased expression was observed for transcripts of several cholinergic receptor subtypes (Chrm2, Chrnb4, and Chrna7), the highaffinity choline transporter $\mathrm{CHT} 1$ (Slc5a7) and the catalytic subunit of calcineurin A (Ppp3cb) (Table 2; Fig. 2). Muscarinic receptor M2 mRNA (Chrm2) displayed the largest variation with an increase expression of $121 \%(\mathrm{FC}=1.21)$. On the other hand, the transcription factor AP2- $\mu 1$ (Ap2m1) was slightly downregulated in oxaliplatintreated rats compared with controls.

Expression of $\mathrm{M} 2$ receptors proteins in the pIC in oxaliplatin-treated rats and SNI rats

The expression of the muscarinic M2 receptor has been assessed at the protein level in the pIC of oxaliplatin-treated rats at day 31 after the first oxaliplatin injection (Fig. 3A). A significant increase of M2 protein expression has been observed in oxaliplatintreated rats compared with controls $(p=0.037)$. To extend this result to another model of neuropathic pain with a different etiology, M2 receptor expression was also assessed in the pIC of SNI rats 1 month after surgery. Consistently, Western blot analysis revealed a significant increased expression of $\mathrm{M} 2$ receptor in the left pIC of SNI rats (i.e., contralateral side of the nerve injury) compared with sham $(p=0.022$, Fig. $3 B)$.
Effect on mechanical allodynia of a muscarinic agonist injection into the pIC

As the mRNA and protein of the muscarinic M2 receptor were upregulated in the pIC of oxaliplatin-treated animals, the influence of muscarinic M2 receptors on mechanical allodynia was assessed using an M2 agonist (oxotremorine) alone or combined with a specific M2 antagonist (methoctramine); both have been microinjected into the pIC. A representative example of the infusion site locations of 20 randomly selected rats is shown in Figure $4 A$. Forty-four rats were finally included in the behavioral analysis. Mixed models revealed a significant effect of treatment $\left(F_{(6,61)}=28.73, p<0.001\right)$, time $\left(F_{(1,61)}=11.47, p<0.001\right)$, and between time and treatment $\left(F_{(6,61)}\right.$ $=4.715, p<0.001)$. Before drug administration (baseline values), mechanical withdrawal thresholds were significantly decreased in all groups of oxaliplatin-treated rats $(p<0.001)$ compared with control rats. After $15 \mathrm{~min}$, oxotremorine infusion significantly increased mechanical withdrawal thresholds in oxaliplatin-treated animals compared with the vehicle-infused group $(p<0.001)$ and baseline values $(p<0.001)$, whereas oxotremorine did not exhibit any effect in the control group ( $5 \%$ glucose). Methoctramine did not induce any changes when administered alone in both groups. However, it significantly prevented oxotremorine antiallodynic effect in oxaliplatin-treated rats (Fig. 4B), confirming the involvement of muscarinic M2 receptors expressed within the pIC. 
Table 2. Differentially expressed genes in the posterior insular cortex of oxaliplatin-treated rats compared with controls using TLDA ${ }^{a}$

\begin{tabular}{|c|c|c|c|c|}
\hline Assay ID & Gene name & Locuslink gene name & Fold change (log2 RQ ratios) & $p$ \\
\hline Rn02532311_s1 & Chrm2 & Cholinergic receptor, muscarinic 2 & 1.21 & 0.016 \\
\hline Rn00591542_m1 & Chrna2 & Cholinergic receptor, nicotinic, alpha 2 (neuronal) & 1.12 & 0.059 \\
\hline Rn00592317_m1 & Chrnb3 & Cholinergic receptor, nicotinic, beta 3 & 0.96 & 0.208 \\
\hline Rn00583822_m1 & Chrnb4 & Cholinergic receptor, nicotinic, beta 4 & 0.7 & 0.027 \\
\hline Rn00569370_m1 & Chrm5 & Cholinergic receptor, muscarinic 5 & 0.67 & 0.059 \\
\hline Rn00585367_m1 & $S / c 5 a 7$ & Solute carrier family 5 (choline transporter), member 7 (CHT1) & 0.64 & 0.046 \\
\hline Rn01453446_m1 & Chat & Choline 0 -acetyltransferase & 0.56 & 0.294 \\
\hline Rn01512482_m1 & $N k \times 2-1$ & NK2 homeobox 1 & 0.5 & 0.172 \\
\hline Rn00581454_s1 & S/c18a3 & Solute carrier family 18 (vesicular acetylcholine), member 3 (VAChT) & 0.38 & 0.401 \\
\hline Rn00566864_m1 & Ppp3cb & Protein phosphatase 3, catalytic subunit, beta isozyme & 0.26 & 0.036 \\
\hline Rn00596883_m1 & Ache & Acetylcholinesterase (ACHE) & 0.23 & 0.115 \\
\hline Rn00567492_m1 & Chka & Choline kinase alpha & 0.23 & 0.074 \\
\hline Rn01512605_s1 & Chrm4 & Cholinergic receptor, muscarinic 4 & 0.22 & 0.172 \\
\hline Rn00560986_s1 & Chrm3 & Cholinergic receptor, muscarinic 3 & 0.21 & 0.059 \\
\hline Rn00487426_g1 & Fos & FBJ osteosarcoma oncogene & 0.2 & 0.462 \\
\hline Rn00563223_m1 & Chrna7 & Cholinergic receptor, nicotinic, alpha 7 & 0.19 & 0.036 \\
\hline Rn00440861_m1 & Prkcg & Protein kinase C, gamma & 0.15 & 0.753 \\
\hline Rn00567155_m1 & Chrna5 & Cholinergic receptor, nicotinic, alpha 5 & 0.13 & 0.401 \\
\hline Rn00572991_s1 & Jun & Jun jun proto-oncogene & 0.09 & 0.6 \\
\hline Rn00690508_m1 & Ppp3ca & Protein phosphatase 3, catalytic subunit, alpha isoform & 0.08 & 0.529 \\
\hline Rn00583820_m1 & Chrna3 & Cholinergic receptor, nicotinic, alpha 3 & 0.07 & 0.753 \\
\hline Hs99999901_s1 & 185 & Eukaryotic 185 rRNA & 0.05 & 0.401 \\
\hline Rn02115682_s1 & Adcy 1 & Adenylate cyclase 1 (brain) & 0.03 & 0.916 \\
\hline Rn01413148_m1 & REST & RE1-silencing transcription factor (NRSF) & 0.03 & 0.6 \\
\hline Rn00566216_m1 & Dnm2 & Dynamin 2 & 0.03 & 1 \\
\hline Rn00570733_m1 & Chrnb2 & Cholinergic receptor, nicotinic, beta 2 (neuronal) & 0.002 & 0.916 \\
\hline Rn00570754_m1 & Cltc & Clathrin, heavy chain $(\mathrm{Hc})$ & -0.04 & 0.674 \\
\hline Rn00820748_g1 & Rplp2 & Ribosomal protein, large P2 & -0.05 & 0.401 \\
\hline Rn01533872_m1 & Ngf & Nerve growth factor (beta polypeptide) & -0.11 & 0.282 \\
\hline Rn00577436_m1 & Chrna4 & Cholinergic receptor, nicotinic, alpha 4 & -0.13 & 0.674 \\
\hline Rn00589936_s1 & Chrm1 & Cholinergic receptor, muscarinic 1 & -0.14 & 0.074 \\
\hline Rn01514511_m1 & Plcb1 & Phospholipase C, beta 1 (phosphoinositide-specific) & -0.21 & 0.248 \\
\hline Rn00587681_m1 & Ap2m1 & Adaptor-related protein complex 2, mu 1 subunit & -0.21 & 0.016 \\
\hline Rn00569203_m1 & $\mid s / 1$ & ISL LIM homeobox 1 & -1.12 & 0.153 \\
\hline
\end{tabular}

${ }^{a}$ Data are expressed as fold changes where 0 equals no change in gene expression and 1 and -1 equal twofold upregulation and downregulation, respectively. Statistical differences between groups were assessed using the nonparametric Mann-Whitney Wilcoxon test.

Effect of oral donepezil on oxaliplatininduced neuropathic pain behavior

The antiallodynic effect of oxotremorine demonstrated the relevance of targeting the pIC cholinergic system, especially M2 receptors, to reduce painful symptoms of oxaliplatin-induced neuropathy. To confirm this result and extend it to a clinically applicable approach, the effect of systemic donepezil, a reversible acetylcholinesterase inhibitor, was assessed on oxaliplatin-induced pain hypersensitivity.

First, the effect of different doses of donepezil on motor coordination was assessed $1 \mathrm{~h}$ after oral administration using the rotarod test. A significant decrease of fall latencies $(-36 \%, p=0.010)$ was observed only in rats treated with the highest dose of donepezil (10 mg/kg, p.o.) compared with vehicle-treated rats (Fig. $5 A$ ). The dose of $5 \mathrm{mg} / \mathrm{kg}$ (p.o.) was therefore chosen for subsequent experiments. After acute administration of donepezil, on day 31 after the first oxaliplatin injection, a significant effect of time $\left(F_{(4,85)}=4.898 ; p=\right.$ $0.0013)$, treatment $\left(F_{(3,85)}=65.140 ; p<0.001\right)$, and interaction between time and treatment $\left(F_{(12,85)}=6.205 ; p<0.001\right)$ were
Chrm2
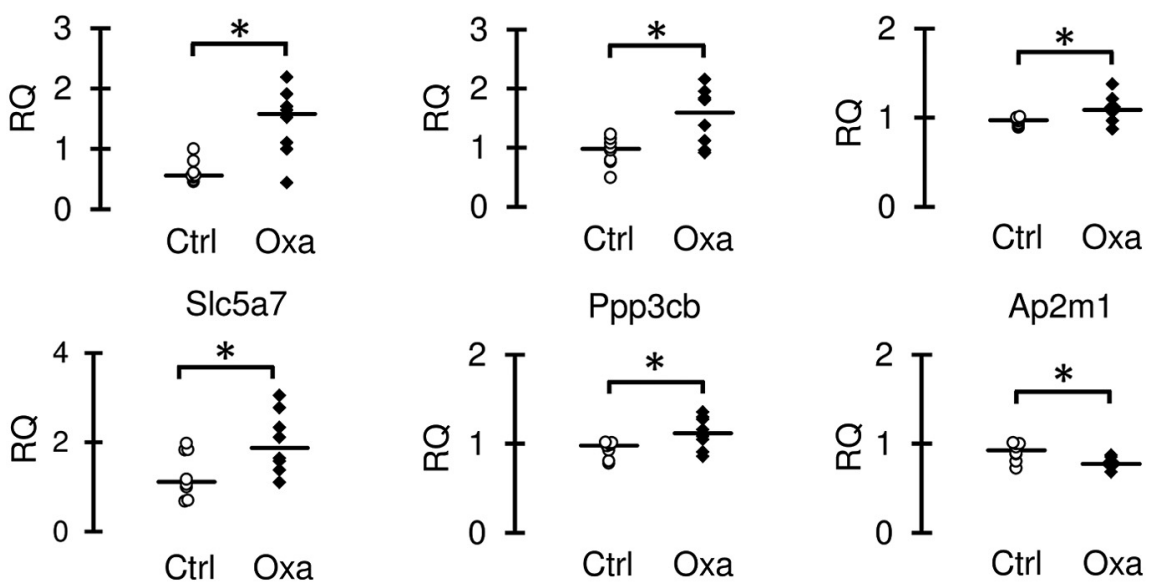

Figure 2. Relative quantity (RQ) scatter plots of the 6 transcripts differentially expressed in the posterior insular cortex between oxaliplatin-treated animals and control rats assessed using TLDA. Horizontal bar represents the median. ${ }^{*} p<0.05$ (nonparametric Mann-Whitney Wilcoxon test). $n=8 /$ group (in duplicate).

found on mechanical thresholds. While donepezil did not change mechanical thresholds in 5\% glucose treated rats, it significantly reversed mechanical allodynia in oxaliplatin-treated rats at T30 $(84 \%, p<0.01)$ and T60 $(90 \%, p<0.01)$ after administration (Fig. $5 C$ ). Similar results were observed on cold allodynia (Fig. 

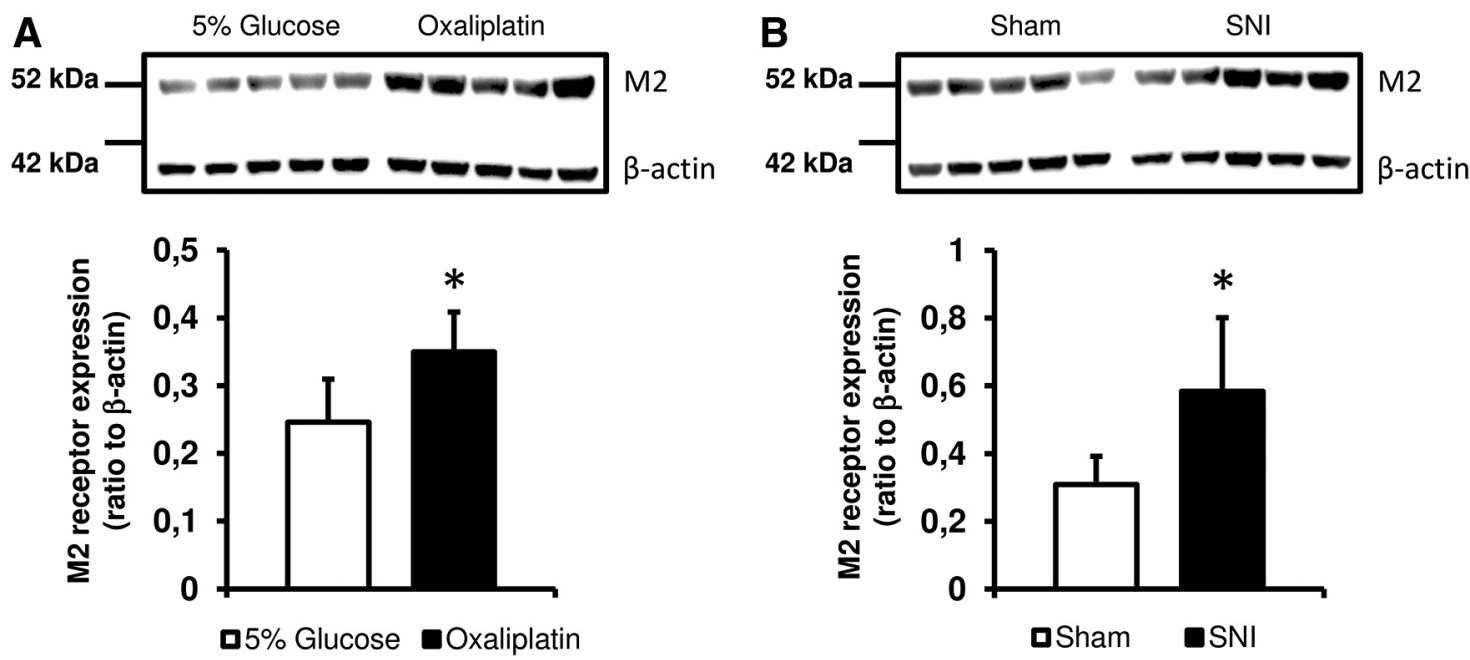

Figure 3. Representative Western blot of the expression of M2 receptor proteins in the left pIC of oxaliplatin-treated rats $(\boldsymbol{A})$ and SNI rats $(\boldsymbol{B})$ compared with matched controls. Histograms of quantification of M2 receptor expression are relative to $\beta$-actin in the two groups. Data are mean \pm SD. ${ }^{*} p<0.05$ (nonparametric Mann-Whitney test). $n=5 /$ group.

A

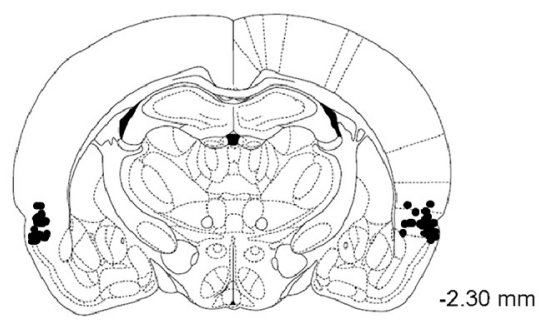

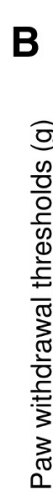

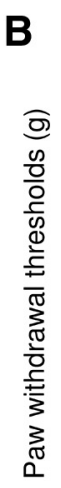

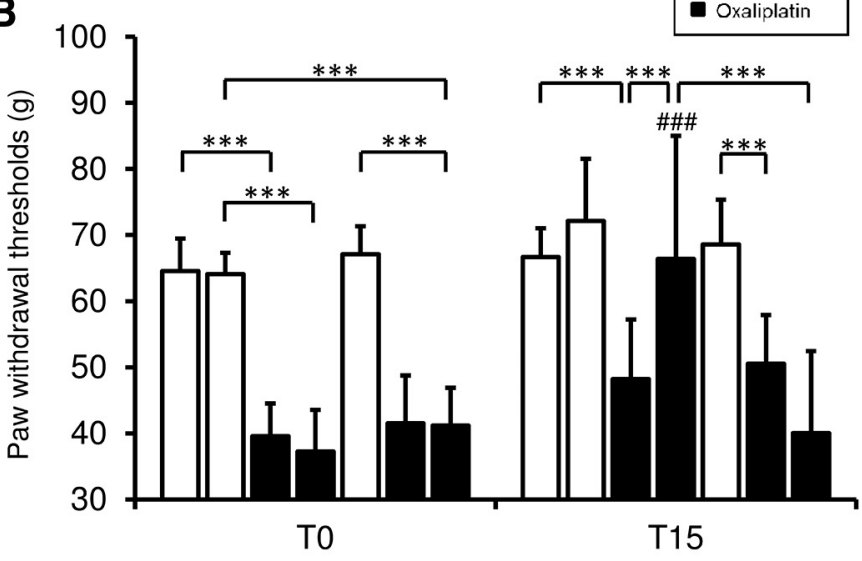

Oxotremorine
$(0.1 \mathrm{nmol})$

Methoctramine

$(30 \mathrm{nmol})$

Figure 4. Effect of $\mathrm{M} 2$ receptor activation in the posterior insular cortex on neuropathic pain. $A$, Location of injection site from a random sample of 20 rats whose behavioral data were included in the statistical analysis. The coordinate is posterior to bregma. $\boldsymbol{B}$, Effect of oxotremorine $(0.1 \mathrm{nmol}, 0.2 \mu \mathrm{l} /$ side) and/or methoctramine $(30 \mathrm{nmol}, 0.2 \mu \mathrm{l} / \mathrm{side})$ infusion in the posterior insular cortex on mechanical withdrawal thresholds $15 \mathrm{~min}$ after the administration at day 31 . Data are mean $\pm S D .{ }^{* * *} p<0.001, \mathrm{~T} 15$ versus baseline values (two-way repeated-measures ANOVA followed by a Tuckey post hoc test). ${ }^{\# \#} p<0.001$, T15 versus baseline values (two-way repeated-measures ANOVA followed by a Tuckey post hoc test). $n=3-7$ per group.

$5 D)$. Analysis of mixed models revealed a significant effect of time $\left(F_{(4,85)}=9.067 ; p<0.001\right)$, treatment $\left(F_{(3,85)}=11.012 ; p<\right.$ $0.001)$, and interaction between time and treatment $\left(F_{(12,85)}=\right.$ $5.249 ; p<0.001)$. As for mechanical allodynia, donepezil markedly reduced cold allodynia in oxaliplatin-treated rats at T30 $(89 \%, p<0.05)$ and T60 (85\%, $p<0.01)$ after administration.

Repeated treatment with donepezil ( $5 \mathrm{mg} / \mathrm{kg}$, p.o., twice a day), administered just before the onset of symptoms, namely, before the fifth oxaliplatin injection (i.e., day 15), totally prevented these symptoms throughout the whole experiment, with scores similar to those of the control group ( $5 \%$ glucose + vehicle) (Fig. $5 E, F)$.

Regarding the social interaction test, a significant difference in the time spent in social interaction was found between the groups $(p=0.0015)$. In oxaliplatin-treated rats, a significant decrease of the time spent in social interaction was observed compared with control rats, which was significantly reversed by donepezil ( $5 \mathrm{mg} / \mathrm{kg}$, p.o., $p<0.01$ ) and devoid of effect in control rats (Fig. $5 B$ ).

\section{Involvement of the pIC in the antiallodynic effect of} oral donepezil

Microdialysis was performed between day 28 and day 32 after the first oxaliplatin administration to evaluate potential changes of Ach level in the pIC following oxaliplatin treatment and ascertain whether donepezil was able to reverse these changes. The baseline release of Ach in the pIC, measured for 150 min before the injection of donepezil, was significantly lower in oxaliplatin-treated rats than in control rats $(0.134 \pm 0.036$ vs $0.196 \pm 0.042 \mathrm{ng} / \mathrm{ml}$, $-32 \%, p=0.0023$; Fig. 6 A). Consistently, following acute donepezil administration, a significant increase in Ach levels was observed in oxaliplatin-treated rats compared with baseline values, 
A

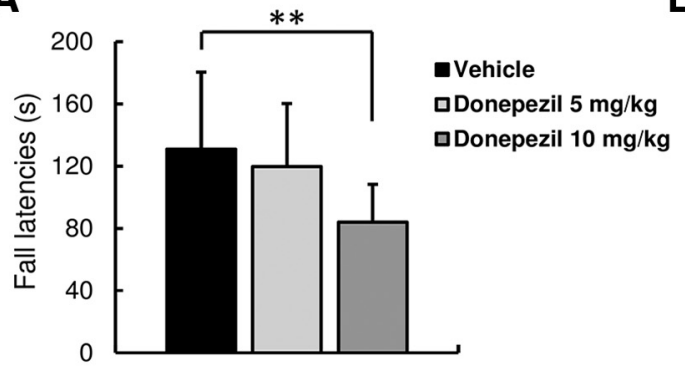

C

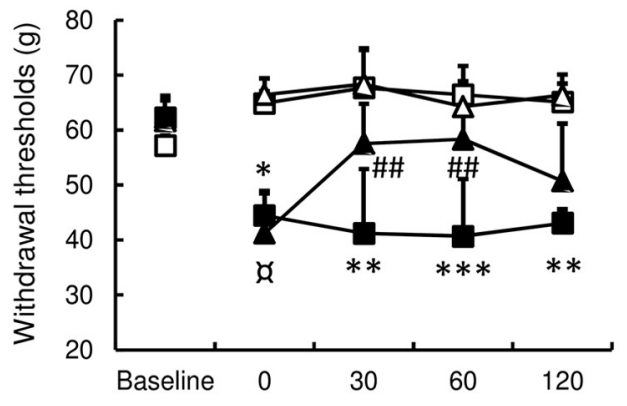

Time after p.o. administration (min)

\section{E}

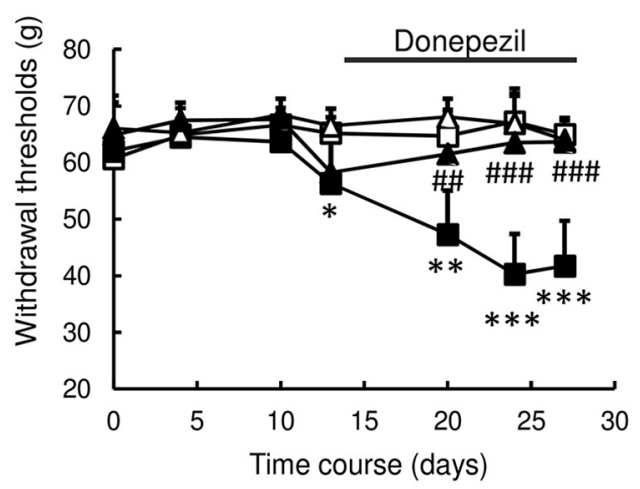

B

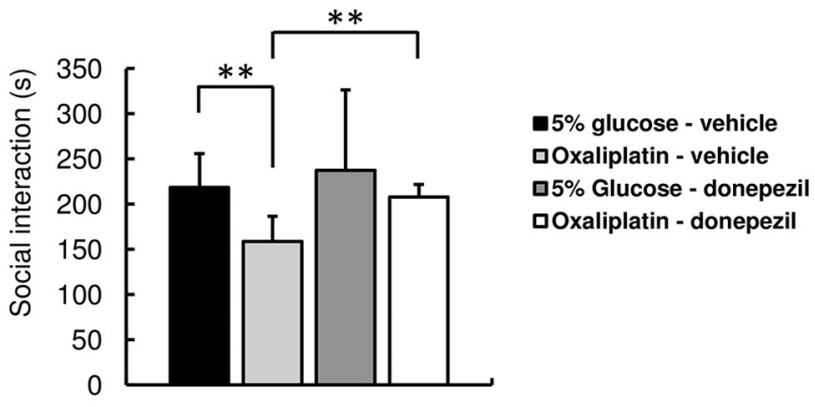

D

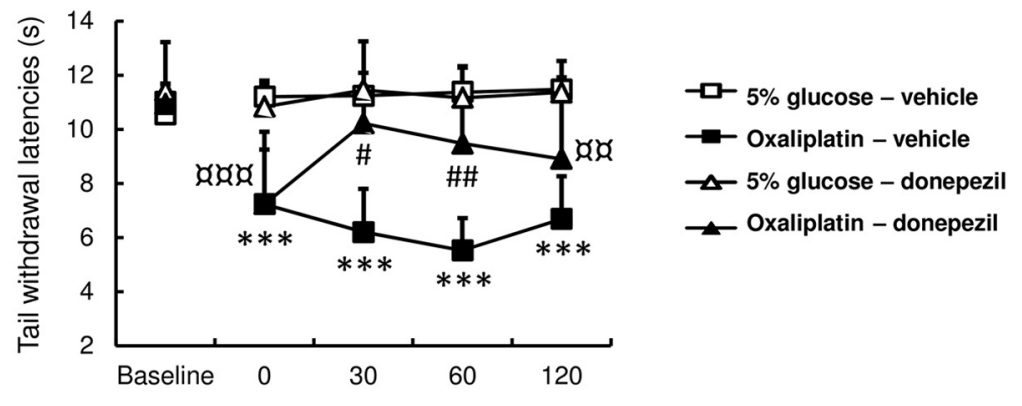

Time after p.o. administration (min)

$\mathbf{F}$

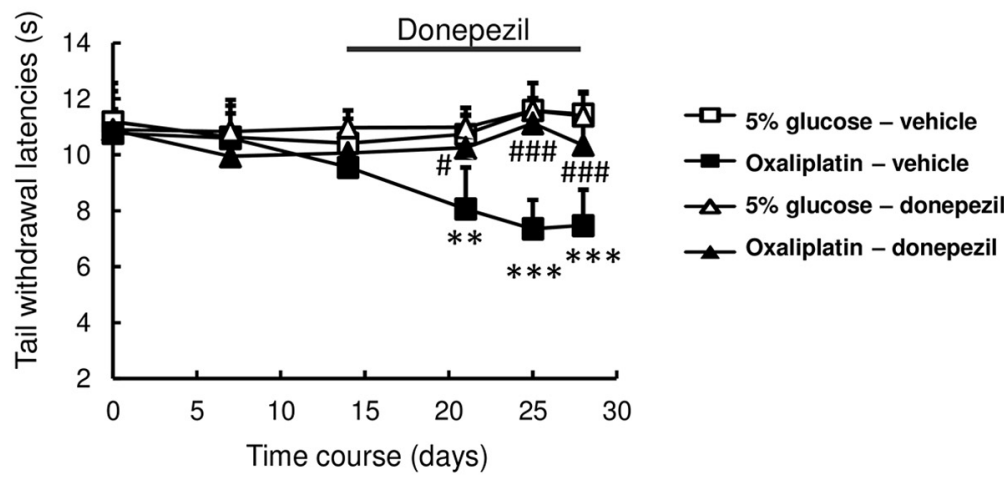

Figure 5. Pharmacological evaluation of oral donepezil on oxaliplatin-induced neuropathy. $A$, Effect of donepezil administration ( $5-10 \mathrm{mg} / \mathrm{kg}, p .0 ., 1 \mathrm{~h}$ before the test) on the time spent on the rotarod in naive rats. ${ }^{* *} p<0.01$, nonparametric Kruskal-Wallis test. $n=8$ /group. $B$, Effect of donepezil administration $(5 \mathrm{mg} / \mathrm{kg}$, p.0., 30 min before the test) on the time spent in social interactions in oxaliplatin-treated rats and controls. ${ }^{* *} p<0.01$ (nonparametric Kruskal-Wallis test). $n=4-14 /$ group. $C, D$, Effect of a single donepezil administration (5 mg/kg, p.o.) on mechanical $(\boldsymbol{C})$ and cold $(\boldsymbol{D})$ allodynia in oxaliplatin-treated rats and controls. $\boldsymbol{E}, \boldsymbol{F}$, Effect of a chronic donepezil administration $(5 \mathrm{mg} / \mathrm{kg}, \mathrm{p} .0$. , twice a day from day 14 to day 28$)$ on the occurrence of mechanical $(\boldsymbol{E})$ and cold $(\boldsymbol{F})$ allodynia in oxaliplatin-treated animals and control rats. Two-way repeated-measures ANOVA followed by a Tukey post hoc test: ${ }^{*} p<0.05$, oxaliplatin-vehicle versus $5 \%$ glucose-vehicle. ${ }^{* *} p<0.01$, oxaliplatin-vehicle versus $5 \%$ glucose-vehicle. ${ }^{* *} p<0.001$, oxaliplatin-vehicle versus $5 \%$ glucose-vehicle. ${ }^{*} p<0.05$, oxaliplatin- donepezil versus $5 \%$ glucose-donepezil. ${ }^{\text {max }} p<0.01$, oxaliplatin-donepezil versus $5 \%$ glucose-donepezil. ${ }^{\text {nox }} p<0.001$, oxaliplatin-donepezil versus $5 \%$ glucose- donepezil. ${ }^{\#} p<0.05$, oxaliplatin-donepezil versus oxaliplatin-vehicle. ${ }^{\#} p<0.01$, oxaliplatin-donepezil versus oxaliplatin-vehicle. ${ }^{\# \#} p<0.001$, oxaliplatin-donepezil versus oxaliplatin-vehicle. $n=8 /$ group.

and in control rats (Fig. 6B), starting $30 \mathrm{~min}$ after donepezil administration, peaking at $45 \mathrm{~min}(984 \%, p=0.0015)$, before reaching a plateau and staying there until the end of the experiment (150 $\mathrm{min})$.

Because of the increase in pIC Ach levels following donepezil administration, and our previous demonstration of the analgesic effect of pIC M2 receptor activation, the involvement of pIC M2 receptors in the antihyperalgesic effect of systemic donepezil was assessed by microinjection of methoctramine into the pIC (Fig. $6 C)$. All rats were treated with oxaliplatin and exhibited a significant decrease of mechanical paw withdrawal thresholds before drug administration (T0) compared with baseline values $(p<$ 0.001 , data not shown). In rats whose $\mathrm{pIC}$ was infused with saline, donepezil (5 mg/kg, p.o.) induced a significant increase of paw withdrawal thresholds compared with T0 (53\%, $p<0.001)$ or injected with its vehicle $(54 \%, p<0.001)$. This effect of donepezil was strongly reduced by methoctramine administration compared with rats treated with donepezil and infused with saline $(-79 \%, p<0.001)$.

This experiment was repeated in the SNI model to confirm the involvement of insular M2 receptors in trauma-induced neuropathic pain and assess the ability of donepezil to reverse the subsequent allodynia (Fig. 6D). All rats underwent sciatic nerve injury and exhibited a significant decrease of mechanical paw withdrawal thresholds before drug administration (T0) compared with baseline values ( $p<0.001$, data not shown). Donepezil administration was also associated with a significant increase of mechanical paw withdrawal thresholds at T30 in rats 
A

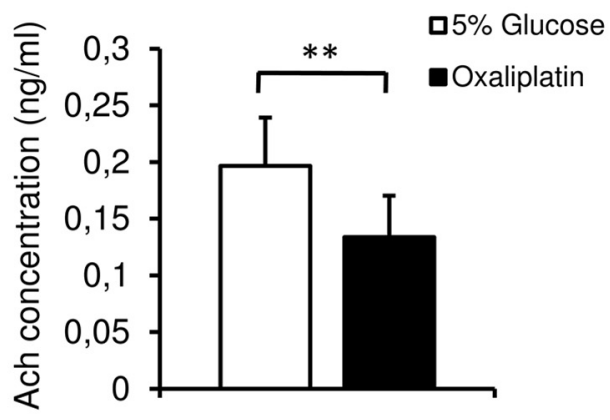

B

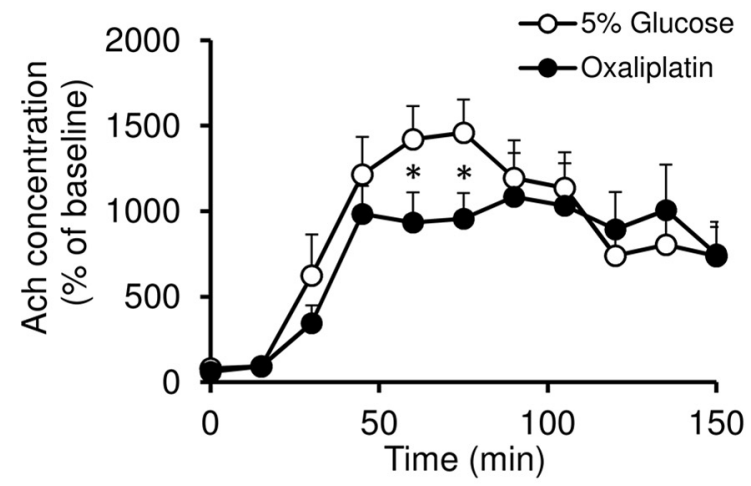

C

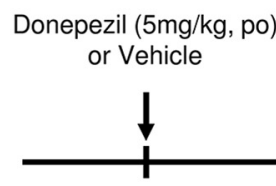

To

Methoctramine (30 $\mathrm{nmol})$ or saline Von Frey testing

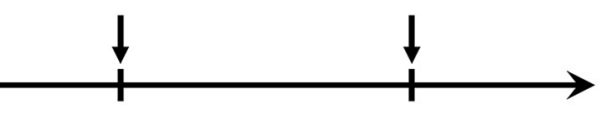

T15

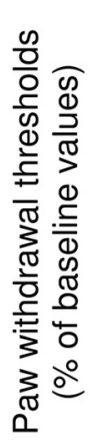
120
110
100
90
80
70
60
50 120
110
100
90
80
70
60
50 $* * * * *$ T0 Donepezil $-\quad++-++$ Methoctramine - + - + - + - +

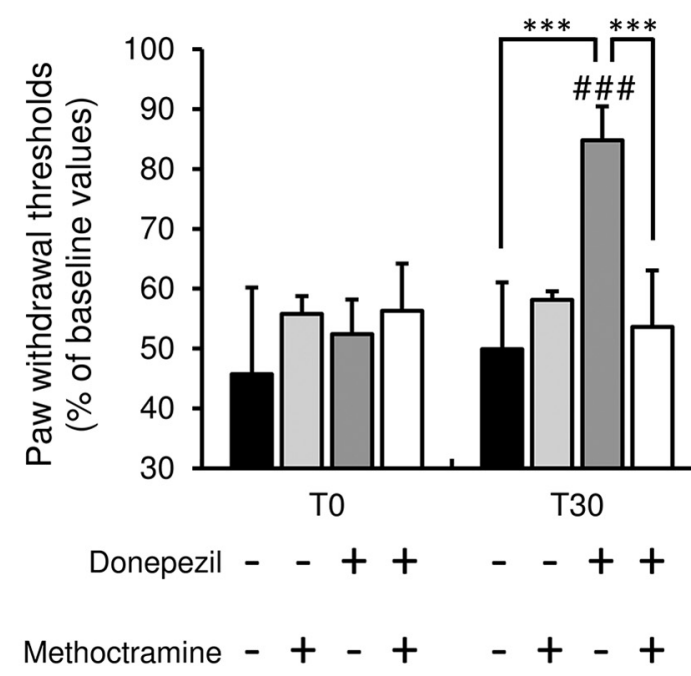

Figure 6. Involvement of the posterior insular cortex in donepezil-induced analgesic effect. $\boldsymbol{A}$, Basal Ach release in the plC in oxaliplatin-treated rats (black) and control rats (white) evaluated by in vivo microdialysis between day 29 and day $31 .{ }^{* *} p<0.01$ (nonparametric Mann-Whitney Wilcoxon test). Data are mean \pm SD; $n=6$ or 7 per group. $\boldsymbol{B}$, Effect of donepezil (5 mg/kg, p.0. injected at T0 min) on Ach concentrations in the pIC of oxaliplatin-treated rats (black dots) and controls (white dots). Data are percentage of baseline values (mean \pm SD). ${ }^{*} p<0.05,0 x a$ liplatin versus $5 \%$ glucose (Student's $t$ test). $n=$ 6 or 7 per group. C, Effect of methoctramine infusion in the plC on donepezil-induced antiallodynic effect in oxaliplatin-treated rats (bottom left panel) and in SNI rats (bottom right panel). Experiments were performed 1 month after induction of neuropathic pain. Top, Experimental design. Mechanical pain thresholds were evaluated at T0 (before any drug dosing) and at T30 min, namely, 30 min after donepezil ( 5 $\mathrm{mg} / \mathrm{kg}$, p.o.) or vehicle administration and $15 \mathrm{~min}$ after methoctramine ( $30 \mathrm{nmol}$ ) or saline infusion in the pIC. ${ }^{* *} p<0.001$, T30 versus T30 (two-way repeated-measures ANOVA followed by a Tukey post hoc test), ${ }^{* *} p<0.01$. ${ }^{\# \# \#} p<0.001$, T30 versus T0 (two-way repeated-measures ANOVA followed by a Tukey post hoc test). ${ }^{\# \#} p<0.01$. Data are mean \pm SD; $n=8$ per group .

infused with saline compared with T0 $(62 \%, p<0.001)$ or injected with its vehicle $(89 \%, p<0.001)$. This antiallodynic effect of donepezil was consistently and significantly inhibited following methoctramine administration compared with rats treated with donepezil and infused with saline $(-45 \%, p<0.001)$.

\section{Discussion}

The aim of this study was to investigate brain neurochemical alterations in an animal model of oxaliplatin-induced neuropathic pain and propose a novel concept for innovative treatments. The main results were the involvement of cholinergic neurotransmission within the $\mathrm{pIC}$ and the positive effect of a direct (oxotremorine) or indirect (donepezil) activation of the pIC M2 muscarinic receptor to reverse oxaliplatin-induced neuropathic pain. Moreover, this latest result was reproduced using a model of traumatic nerve injury, thus generalizing this mechanism to neuropathic pain arising from peripheral nerve injury.

Metabolic changes were mainly found in the pIC, which has been shown to be reciprocally connected to both primary and secondary somatosensory cortices and the posterior thalamic nucleus (Shi and Cassell, 1998). The insular cortex is increasingly considered as a major somatosensory area for pain processing in humans (Garcia-Larrea et al., 2010; Isnard et al., 2011, Segerdahl et al., 2015) and has been recently shown to be involved in the pathophysiology of chemotherapy-induced neuropathic pain (Boland et al., 2014). This brain structure is also involved in animal models of peripheral painful neuropathy (Benison et al., 2011; Coffeen et al., 2011). Furthermore, a form of NMDAdependent synaptic plasticity has been observed in the pIC following peripheral nerve injury in mice (Qiu et al., 2013). Thus, 
the metabolic changes observed in the pIC of oxaliplatin-treated animals might also reflect plastic changes involved in pain sensitization. Nonetheless, the absence of notable metabolic variations in other cortical areas known to be involved in chronic pain may be due to a lack of sensitivity of the NMR-HRMAS technique but most likely to a smaller impact of pain-induced plasticity of oxaliplatin on the global metabolome of these structures.

One of the neurochemical variations observed in the pIC was an increased concentration of choline in oxaliplatin-treated rats compared with controls. Importantly, only the choline concentration was correlated with mechanical pain thresholds, suggesting a causal link between choline level in the pIC and oxaliplatin-induced mechanical allodynia. Choline is a key precursor of glycerophospholipids and is therefore considered as an indicator of membrane integrity (Rudkin and Arnold, 1999). However, the lack of variation of GPC and PC concentrations in this structure is inconsistent with membrane breakdown, as described previously (Klein, 2000). Choline is also a precursor/metabolite of Ach, a major neurotransmitter of the nervous system. As suggested previously, the change of choline signal observed in magnetic resonance spectroscopy may correlate with a modification of the concentration of Ach (Wang et al., 2008). The neocortex receives a dense cholinergic innervation from the basal forebrain (Eckenstein et al., 1988), which plays crucial role in several physiological functions, ranging from attention ( $\mathrm{Yu}$ and Dayan, 2005) to memory (Banks et al., 2012), but also cortical pain processing (Ortega-Legaspi et al., 2010).

To investigate more directly any potential alteration in Ach metabolism and/or cholinergic neurotransmission in the oxaliplatin neuropathic pain model, the expression of 34 genes associated with Ach metabolism and effects was assessed. An increased expression of the high-affinity choline transporter (CHT) was found in the pIC of oxaliplatin-treated rats compared with controls. CHT is exclusively expressed in cholinergic neurons and is essential for choline recycling, which is believed to be the ratelimiting step for Ach synthesis (Misawa et al., 2001; Sarter and Parikh, 2005). Consequently, CHT activity is considered to be a marker of cholinergic neurotransmission status and its upregulation is in line with the observed changes in Ach metabolism (Atweh et al., 1975; Sarter and Parikh, 2005). In addition, we observed increased mRNA levels of the nicotinic receptor subunits $\alpha 7$ and $\beta 4$ and especially the M2 muscarinic receptor. This increased expression of $\mathrm{M} 2$ receptors was confirmed at the protein level using Western blot analysis in oxaliplatin-treated rats but also in SNI rats. The M2 receptors are predominantly presynaptic Ach receptors that decrease neurotransmitter release by inhibiting adenylyl cyclase and/or indirectly decreasing calcium influx into nerve terminals (Krejci et al., 2004). M2 receptors have also been shown to be expressed on glutamatergic neurons in the cerebral cortex, either presynaptically or postsynaptically (Mrzljak et al., 1993). Numerous studies have demonstrated the role of Ach in the modulation of EPSPs in pyramidal neurons of the neocortex (Kimura and Baughman, 1997; Levy et al., 2006), which involves presynaptic M2 muscarinic receptors (Levy et al., 2006; Xiao et al., 2009). Therefore, excitatory transmission could be affected by changes in the cholinergic system, such as M2 receptor expression and/or Ach release within the pIC, ultimately modifying pain perception.

To determine the ability of M2 muscarinic receptor activation expressed in the pIC in relieving pain hypersensitivity, the effect of the nonselective muscarinic agonist oxotremorine directly injected in this structure was evaluated. A very low dose of oxotremorine completely reversed oxaliplatin-induced mechanical allodynia. Intracerebroventricular injection of $10 \mu \mathrm{g}$ of oxotremorine has also been shown to produce antinociception in mice (Duttaroy et al., 2002). However, no analgesic effect has been observed in control rats receiving oxotremorine, suggesting a specific role of the $\mathrm{pIC}$ in neuropathic pain processing. This observation is consistent with other studies showing that discrete lesion of the insular cortex reverses mechanical allodynia associated with peripheral nerve injury without affecting nociceptive thresholds in normal rats (Benison et al., 2011; Coffeen et al., 2011). Importantly, the effect of oxotremorine in oxaliplatintreated rats was completely prevented by methoctramine, demonstrating the key role of pIC M2 receptors. In diabetic rats, mechanical allodynia is also associated with an upregulation of muscarinic M2 receptors in the spinal dorsal horn and an increased antinociceptive effect of intrathecal muscarinic agonist administration (Chen and Pan, 2003). Similarly, an increased expression of M2 receptors has been observed in DRG neurons and, presumably, in their central terminals in a rat model of peripheral nerve injury (Hayashida et al., 2006). This upregulation could be responsible for the increased efficacy of cholinesterase inhibitors in relieving mechanical allodynia (Hwang et al., 1999).

The effect of systemic administration of donepezil, an acetylcholinesterase inhibitor, on oxaliplatin-induced allodynia was then assessed. When acutely administered after the completion of oxaliplatin-based chemotherapy, donepezil reversed mechanical and cold allodynia and the alteration of social interaction associated with neuropathic pain. Chronic treatment starting at the onset of symptoms also completely prevented their development. Moreover, acute donepezil administration 1 month after nerve injury largely reduced mechanical allodynia in SNI rats. Several preclinical studies have already established the interest of donepezil and other cholinesterase inhibitors for the treatment of neuropathic pain (Clayton et al., 2007; Kimura et al., 2013). In a rat model of spinal nerve ligation (SNL), donepezil administration results in an attenuation of mechanical hyperalgesia through a spinal muscarinic mechanism (Clayton et al., 2007). This analgesic effect could also involve spinal nicotinic and GABAergic receptors, but it is still unclear whether this effect of donepezil is directly due to an increase of spinal Ach release (Kimura et al., 2013). Indeed, cholinergic analgesia is only observed in neuropathic pain conditions, but the peak level and the time course of the Ach increase after donepezil treatment using spinal microdialysis were similar between normal and SNL rats (Kimura et al., 2013). Furthermore, the spinal basal levels of ACh were not significantly different between normal and SNL rats. However, in our study, microdialysis revealed, for the first time, a significant reduction of basal Ach release in the pIC of oxaliplatin-treated rats compared with control rats. The administration of donepezil is able to increase synaptic concentration of Ach in the pIC in oxaliplatin-treated rats, but it was still significantly lower than in control animals. Therefore, the analgesic effect of donepezil via Ach release might be mainly due to the upregulation of M2 receptors in oxaliplatin-treated rats and, presumably, in SNI rats. As mentioned above, M2 muscarinic receptors have been reported to play an essential role in cholinergic analgesia (Gomeza et al., 1999; Bernardini et al., 2001) and an increased expression of these receptors, as found in the $\mathrm{pIC}$, has been observed at central and peripheral levels following peripheral nerve injury (Hayashida et al., 2006). Consistently, the antinociceptive effect of donepezil in both models of neuropathic pain was reversed by local administration of a specific M2 antagonist within the pIC. Therefore, in a neuropathic pain context, antinociception could 
be achieved by using centrally active cholinesterase inhibitors, which would result in an increased brain Ach concentration, ultimately leading to the activation of upregulated cortical pIC M2 receptors. The change of M2 expression could be a key point in the analgesic effect of donepezil rather than Ach availability (Hayashida et al., 2006; Kimura et al., 2013).

In conclusion, our study describes, for the first time, the presence of discrete metabolic variations in the pain matrix in an animal model of chemotherapy-induced neuropathy, especially an increase of choline concentration in the pIC directly correlated with mechanical allodynia. Neuropathic pain was also associated with a decrease of Ach release in oxaliplatin-treated rats, and an upregulation of M2 receptors in the PIC was observed in both models used. Accordingly, analgesia was achieved following direct $\mathrm{M} 2$ receptor activation in oxaliplatin-treated rats and the systemic administration of donepezil, a cholinesterase inhibitor, in both models. Hence, targeting the cortical cholinergic system using centrally acting cholinomimetic drugs could represent a promising and innovative strategy for the therapeutic management of neuropathic pain.

\section{References}

André T, Boni C, Mounedji-Boudiaf L, Navarro M, Tabernero J, Hickish T, Topham C, Zaninelli M, Clingan P, Bridgewater J, Tabah-Fisch I, de Gramont A (2004) Oxaliplatin, fluorouracil, and leucovorin as adjuvant treatment for colon cancer. N Engl J Med 350:2343-2351. CrossRef Medline

Apkarian AV, Sosa Y, Sonty S, Levy RM, Harden RN, Parrish TB, Gitelman DR (2004) Chronic back pain is associated with decreased prefrontal and thalamic gray matter density. J Neurosci 24:10410-10415. CrossRef Medline

Atweh S, Simon JR, Kuhar MJ (1975) Utilization of sodium-dependent high affinity choline uptake in vitro as a measure of the activity of cholinergic neurons in vivo. Life Sci 17:1535-1544. CrossRef Medline

Banks PJ, Bashir ZI, Brown MW (2012) Recognition memory and synaptic plasticity in the perirhinal and prefrontal cortices. Hippocampus 22: 2012-2031. CrossRef Medline

Benison AM, Chumachenko S, Harrison JA, Maier SF, Falci SP, Watkins LR, Barth DS (2011) Caudal granular insular cortex is sufficient and necessary for the long-term maintenance of allodynic behavior in the rat attributable to mononeuropathy. J Neurosci 31:6317-6328. CrossRef Medline

Bernardini N, Reeh PW, Sauer SK (2001) Muscarinic M2 receptors inhibit heat-induced CGRP release from isolated rat skin. Neuroreport 12: 2457-2460. CrossRef Medline

Boland EG, Selvarajah D, Hunter M, Ezaydi Y, Tesfaye S, Ahmedzai SH, Snowden JA, Wilkinson ID (2014) Central pain processing in chronic chemotherapy-induced peripheral neuropathy: a functional magnetic resonance imaging study. PLoS One 9:e96474. CrossRef Medline

Burgmer M, Gaubitz M, Konrad C, Wrenger M, Hilgart S, Heuft G, Pfleiderer B (2009) Decreased gray matter volumes in the cingulo-frontal cortex and the amygdala in patients with fibromyalgia. Psychosom Med 71: 566-573. CrossRef Medline

Chen SR, Pan HL (2003) Up-regulation of spinal muscarinic receptors and increased antinociceptive effect of intrathecal muscarine in diabetic rats. J Pharmacol Exp Ther 307:676-681. CrossRef Medline

Clayton BA, Hayashida K, Childers SR, Xiao R, Eisenach JC (2007) Oral donepezil reduces hypersensitivity after nerve injury by a spinal muscarinic receptor mechanism. Anesthesiology 106:1019-1025. CrossRef Medline

Cobos EJ, Portillo-Salido E (2013) "Bedside-to-bench" behavioral outcomes in animal models of pain: beyond the evaluation of reflexes. Curr Neuropharmacol 11:560-591. CrossRef Medline

Coffeen U, Manuel Ortega-Legaspi J, López-Muñoz FJ, Simón-Arceo K, Jaimes O, Pellicer F (2011) Insular cortex lesion diminishes neuropathic and inflammatory pain-like behaviours. Eur J Pain 15:132-138. CrossRef Medline

DaSilva AF, Becerra L, Pendse G, Chizh B, Tully S, Borsook D (2008) Colocalized structural and functional changes in the cortex of patients with trigeminal neuropathic pain. PLoS One 3:e3396. CrossRef Medline
Decosterd I, Woolf CJ (2000) Spared nerve injury: an animal model of persistent peripheral neuropathic pain. Pain 87:149-158. CrossRef Medline

Duttaroy A, Gomeza J, Gan JW, Siddiqui N, Basile AS, Harman WD, Smith PL, Felder CC, Levey AI, Wess J (2002) Evaluation of muscarinic agonist-induced analgesia in muscarinic acetylcholine receptor knockout mice. Mol Pharmacol 62:1084-1093. CrossRef Medline

Eckenstein FP, Baughman RW, Quinn J (1988) An anatomical study of cholinergic innervation in rat cerebral cortex. Neuroscience 25:457-474. CrossRef Medline

Fauvelle F, Dorandeu F, Carpentier P, Foquin A, Rabeson H, GraveronDemilly D, Arvers P, Testylier G (2010) Changes in mouse brain metabolism following a convulsive dose of soman: a proton HRMAS NMR study. Toxicology 267:99-111. CrossRef Medline

Garcia-Larrea L, Perchet C, Creac'h C, Convers P, Peyron R, Laurent B, Mauguière F, Magnin M (2010) Operculo-insular pain (parasylvian pain): a distinct central pain syndrome. Brain 133:2528-2539. CrossRef Medline

Gomeza J, Shannon H, Kostenis E, Felder C, Zhang L, Brodkin J, Grinberg A, Sheng H, Wess J (1999) Pronounced pharmacologic deficits in M2 muscarinic acetylcholine receptor knockout mice. Proc Natl Acad Sci U S A 96:1692-1697. CrossRef Medline

Govindaraju V, Young K, Maudsley AA (2000) Proton NMR chemical shifts and coupling constants for brain metabolites. NMR Biomed 13:129-153. CrossRef Medline

Graveron-Demilly D (2014) Quantification in magnetic resonance spectroscopy based on semi-parametric approaches. Magma 27:113-130. CrossRef Medline

Graveron-Demilly D, Diop A, Briguet A, Fenet B (1993) Product-operator algebra for strongly coupled spin systems. J Magn Reson Series A 101: 233-239. CrossRef

Grégoire S, Wattiez AS, Etienne M, Marchand F, Ardid D (2014) Monoarthritis-induced emotional and cognitive impairments in rats are sensitive to low systemic doses or intra-amygdala injections of morphine. Eur J Pharmacol 735:1-9. CrossRef Medline

Gustin SM, Wrigley PJ, Siddall PJ, Henderson LA (2010) Brain anatomy changes associated with persistent neuropathic pain following spinal cord injury. Cereb Cortex 20:1409-1419. CrossRef Medline

Hayashida KI, Bynum T, Vincler M, Eisenach JC (2006) Inhibitory M2 muscarinic receptors are upregulated in both axotomized and intact small diameter dorsal root ganglion cells after peripheral nerve injury. Neuroscience 140:259-268. CrossRef Medline

Hershman DL, Lacchetti C, Dworkin RH, Lavoie Smith EM, Bleeker J, Cavaletti G, Chauhan C, Gavin P, Lavino A, Lustberg MB, Paice J, Schneider B, Smith ML, Smith T, Terstriep S, Wagner-Johnston N, Bak K, Loprinzi CL (2014) Prevention and management of chemotherapy-induced peripheral neuropathy in survivors of adult cancers: American Society of Clinical Oncology clinical practice guideline. J Clin Oncol 32:1941-1967. CrossRef Medline

Hwang JH, Hwang KS, Leem JK, Park PH, Han SM, Lee DM (1999) The antiallodynic effects of intrathecal cholinesterase inhibitors in a rat model of neuropathic pain. Anesthesiology 90:492-499. CrossRef Medline

Isnard J, Magnin M, Jung J, Mauguière F, Garcia-Larrea L (2011) Does the insula tell our brain that we are in pain? Pain 152:946-951. CrossRef Medline

Kilkenny C, Browne W, Cuthill IC, Emerson M, Altman DG (2010) Animal research: reporting in vivo experiments: the ARRIVE guidelines. $\mathrm{Br} \mathrm{J}$ Pharmacol 160:1577-1579. CrossRef Medline

Kimura F, Baughman RW (1997) Distinct muscarinic receptor subtypes suppress excitatory and inhibitory synaptic responses in cortical neurons. J Neurophysiol 77:709-716. Medline

Kimura M, Hayashida K, Eisenach JC, Saito S, Obata H (2013) Relief of hypersensitivity after nerve injury from systemic donepezil involves spinal cholinergic and gamma-aminobutyric acid mechanisms. Anesthesiology 118:173-180. CrossRef Medline

Klein J (2000) Membrane breakdown in acute and chronic neurodegeneration: focus on choline-containing phospholipids. J Neural Transm 107: 1027-1063. CrossRef Medline

Krejci A, Michal P, Jakubik J, Ricny J, Dolezal V (2004) Regulation of signal transduction at M2 muscarinic receptor. Physiol Res 53 [Suppl 1]:S131-S140.

Kuchinad A, Schweinhardt P, Seminowicz DA, Wood PB, Chizh BA, Bushnell MC (2007) Accelerated brain gray matter loss in fibromyalgia patients: 
premature aging of the brain? J Neurosci 27:4004-4007. CrossRef Medline

Levy RB, Reyes AD, Aoki C (2006) Nicotinic and muscarinic reduction of unitary excitatory postsynaptic potentials in sensory cortex: dual intracellular recording in vitro. J Neurophysiol 95:2155-2166. Medline

Ling B, Authier N, Balayssac D, Eschalier A, Coudore F (2007) Behavioral and pharmacological description of oxaliplatin-induced painful neuropathy in rat. Pain 128:225-234. CrossRef Medline

Livak KJ, Schmittgen TD (2001) Analysis of relative gene expression data using real-time quantitative PCR and the 2(-delta delta C(T)) method. Methods 25:402-408. CrossRef Medline

Misawa H, Nakata K, Matsuura J, Nagao M, Okuda T, Haga T (2001) Distribution of the high-affinity choline transporter in the central nervous system of the rat. Neuroscience 105:87-98. CrossRef Medline

Mrzljak L, Levey AI, Goldman-Rakic PS (1993) Association of m1 and m2 muscarinic receptor proteins with asymmetric synapses in the primate cerebral cortex: morphological evidence for cholinergic modulation of excitatory neurotransmission. Proc Natl Acad Sci U S A 90:5194-5198. CrossRef Medline

Ortega-Legaspi JM, León-Olea M, de Gortari P, Amaya MI, Coffeen U, Simón-Arceo K, Pellicer F (2010) Expression of muscarinic M1 and M2 receptors in the anterior cingulate cortex associated with neuropathic pain. Eur J Pain 14:901-910. CrossRef Medline

Paxinos G, Watson C (1998) The rat brain in stereotaxic coordinates, Ed 4. San Diego: Academic.

Power AE, McIntyre CK, Litmanovich A, McGaugh JL (2003) Cholinergic modulation of memory in the basolateral amygdala involves activation of both $\mathrm{m} 1$ and $\mathrm{m} 2$ receptors. Behav Pharmacol 14:207-213. CrossRef Medline

Qiu S, Chen T, Koga K, Guo YY, Xu H, Song Q, Wang JJ, Descalzi G, Kaang BK, Luo JH, Zhuo M, Zhao MG (2013) An increase in synaptic NMDA receptors in the insular cortex contributes to neuropathic pain. Sci Signal 6:ra34. CrossRef Medline

Ratiney H, Coenradie Y, Cavassila S, van Ormondt D, Graveron-Demilly D (2004) Time-domain quantitation of $1 \mathrm{H}$ short echo-time signals: background accommodation. Magma 16:284-296. CrossRef Medline

Ratiney H, Sdika M, Coenradie Y, Cavassila S, van Ormondt D, GraveronDemilly D (2005) Time-domain semi-parametric estimation based on a metabolite basis set. NMR Biomed 18:1-13. CrossRef Medline

Raymond E, Chaney SG, Taamma A, Cvitkovic E (1998a) Oxaliplatin: a review of preclinical and clinical studies. Ann Oncol 9:1053-1071. CrossRef Medline
Raymond E, Faivre S, Woynarowski JM, Chaney SG (1998b) Oxaliplatin: mechanism of action and antineoplastic activity. Semin Oncol 25 [Supp] 5]:4-12. Medline

Reddy SM, Vergo MT, Paice JA, Kwon N, Helenowski IB, Benson AB, Mulcahy MF, Nimeiri HS, Harden RN (2015) Quantitative sensory testing at baseline and during cycle 1 oxaliplatin infusion detects subclinical peripheral neuropathy and predicts clinically overt chronic neuropathy in gastrointestinal malignancies. Clin Colorectal Cancer 2015:piiS 1533-0028(15)00092-4. CrossRef Medline

Rudkin TM, Arnold DL (1999) Proton magnetic resonance spectroscopy for the diagnosis and management of cerebral disorders. Arch Neurol 56:919-926. CrossRef Medline

Sarter M, Parikh V (2005) Choline transporters, cholinergic transmission and cognition. Nat Rev Neurosci 6:48-56. CrossRef Medline

Segerdahl AR, Mezue M, Okell TW, Farrar JT, Tracey I (2015) The dorsal posterior insula subserves a fundamental role in human pain. Nat Neurosci 18:499-500. CrossRef Medline

Shi CJ, Cassell MD (1998) Cortical, thalamic, and amygdaloid connections of the anterior and posterior insular cortices. J Comp Neurol 399: 440-468. CrossRef Medline

Stefan D, Di Cesare F, Andrasescu A, Popa E, Lazariev A, Vescovo E, Strbak O, Williams S, Starcuk Z, Cabanas M, van Ormondt D, Graveron-Demilly D (2009) Quantitation of magnetic resonance spectroscopy signals: the jMRUI software package. Meas Sci Tech 20.

Tofthagen C (2010) Surviving chemotherapy for colon cancer and living with the consequences. J Palliative Med 13:1389-1391. CrossRef Medline

Tofthagen C, McAllister RD, McMillan SC (2011) Peripheral neuropathy in patients with colorectal cancer receiving oxaliplatin. Clin J Oncol Nurs 15:182-188. CrossRef Medline

Wang XC, Du XX, Tian Q, Wang JZ (2008) Correlation between choline signal intensity and acetylcholine level in different brain regions of rat. Neurochem Res 33:814-819. CrossRef Medline

Weickhardt A, Wells K, Messersmith W (2011) Oxaliplatin-induced neuropathy in colorectal cancer. J Oncol 2011:201593. CrossRef Medline

Xiao Z, Deng PY, Yang C, Lei S (2009) Modulation of GABAergic transmission by muscarinic receptors in the entorhinal cortex of juvenile rats. J Neurophysiol 102:659-669. CrossRef Medline

Yu AJ, Dayan P (2005) Uncertainty, neuromodulation, and attention. Neuron 46:681-692. CrossRef Medline

Zapata A, Chefer VI, Shippenberg TS (2009) Microdialysis in rodents. Curr Protoc Neurosci Chapter 7:Unit7.2. CrossRef Medline 